J. W. GONGGRYP \& C. DUBELAAR

\title{
DE GESCHRIFTEN VAN AFAKA IN ZIJN DJOEKA-SCHRIFT
}

Een onzer heeft in de eerste aflevering van de Nieuwe WestIndische Gids ${ }^{1}$ een overzicht gegeven van de ontwikkeling van het Djoeka-schrift van AFAKA, waarna wij in het Kerstnummer I960 van het Surinaamse maandblad $O p b o u w^{2}$ enige nadere gegevens publiceerden.

In de Nieuwe West-Indische Gids was in een naschrift gezegd, dat wij niet in staat waren wijs te worden uit een zakboekje in het bezit van de Aukaner kapitein Alofaisie van Godoholo, zoon van ABÉNA, de broer en medestander van AFAKA. Laatstgenoemde had het schrift in I9Io, of een paar jaar tevoren bedacht. Zoals in Opbouw is uiteengezet ontdekten wij, dat het boekje van ALOFAISIE, dat geschreven zou zijn door zijn vader ABÉNA, niet gelezen moest worden op de linkerbladzijde en dan van de voet van die bladzijde naar de bovenkant van de rechterbladzijde, maar dat de regels van de linkerbladzijde doorgingen op de rechterbladzijde. De halve regels op elke bladzijde achter elkaar gelezen hadden dus geen zin.

Door de welwillendheid van Monseigneur St. KuYPERS, de Bisschop van Suriname, konden wij vervolgens uit het bisschoppelijk archief van Paramaribo de beschikking krijgen over nagelaten papieren van wijlen Pater F. MoRssink, CssR, waaronder twee zakboekjes beschreven met het Djoeka-schrift. Hier vonden wij de verloren geachte Catechismus, door Pater Monssink meer dan veertig jaren geleden opgesteld, en transcripties in Djoekaschrift van de voornaamste Katholieke gebeden en geloofsformules in Djoeka-taal, overeenkomende met het boekje Passi Foe $\mathrm{Hemel}^{3}$, door de Katholieke Missie uitgegeven voor het

1 J. W. GoNGgryp: The evolution of a Djuka-script in Surinam. N.W.I. G. 40,1960, p. $63-72,5$ afb.

2 J. W. Gonggryp \& C. Dubelaar: Pater Morssink en Afaka. Opbouw (Kerstnummer) 1960, $4 \mathrm{afb}$.

3 Passi Foe Hemel, Wan begi boekoe foe den Roomsoe Katoliki soema. Drukkerij van het Missiehuis Steyl, Holland; Paramaribo, I Januari 1936. 
kustgebied van Suriname. Was dit al belangrijk, van nog meer gewicht vonden wij de bladzijden met afschriften van de hand van Pater MoRssink in Djoeka-schrift van geschriften van AFAKA, in het jaar vóór diens overlijden op 8 juli I9I8 aan de Pater ter hand gesteld. Het zou documentair beter zijn als wij de originele stukken van de hand van AFAKA zelf hadden kunnen reproduceren. Echter, de geschriften van Pater MoRssink in Latijns schrift kunnen met recht gecalligrafeerd genoemd worden. Hij was een buitengewoon betrouwbaar en zich van zijn verantwoordelijkheid bewuste persoonlijkheid. Wij menen derhalve volkomen op de exactheid van zijn afschriften te mogen vertrouwen. Pater MoRssink heeft AFAKA zo nauwkeurig gevolgd, dat hij ook afwijkingen in de vorm of stand van de tekens van die in de oorspronkelijke sleutel van AFAKA zelf heeft gecopiëerd. Dit maakte het lezen voor ons soms wat moeilijker. Daarom wordt hier bijgevoegd een nieuwe sleutel met de voornaamste varianten van de schrifttekens die wij tegen kwamen.

Voor AFAKA was blijkbaar de vorm van een symbool alles wat ter zake deed. Hij zette vaak een teken ondersteboven of op een zijkant; of gebruikte het spiegelbeeld. Voor ons, die gewoon zijn onze schrifttekens een vaste stand te geven, blijkt zonder meer de bovenkant van de bladzijde. Volgens het systeem van AFAKA moet men de boven- of onderkant van de bladzijde op een andere manier aangeven. Aldus is het aangeven van de onderkant van de bladzijde door AFAKA's golflijn logisch verklaard.

Met enkele uitzonderingen, bestaat alles wat tot dusverre in het schrift van AFAKA is gepubliceerd uit enkele regels, soms kattebelletjes zonder veel belang.

W. F. VAN LIER ${ }^{1}$ zegt (p. I59): "Het Djoeka-schrift voor het Negerengelsch, waarvan BonNE en MORTON C. KAHN staaltjes geven, is, naar het schijnt, niet van ouden datum, en geenszins in algemeen gebruik." VAN LIER was door zijn jarenlang verblijf bij de Aucaners, verscheidene jaren als posthouder voor het Gouvernement, uitstekend in staat om zich precies op de hoogte te stellen van dit nieuwe schrift. Het geestelijk leven van een groep mensen bestaat geenszins uit alleen oude gebruiken en overleveringen, maar toch zeker ook uit een zo gewichtig moment als het ontstaan, met veel of weinig succes, van een schrift, waarmede dat geestelijk leven door hen zelf vastgelegd kan worden. Maar de gegeven aanhaling is alles wat VAN LIER ervan vertelt. Granman AMAKTIE, het opperhoofd van de stam, vond AFAKA

1 W. F. van LiER: ‘Aanteekeningen over het geestelijk leven der Djoeka's (Aukaner Boschnegers) in Suriname', met een inleiding en gegevens door C. H. DE GoEJE; Bijdr. Taal- Land-en Volkenkunde, 1940, p. 131-294. 
een 'vent van niks' (wissi-wassi-man). Als bewijs daarvoor wilde hij AFAKA een brief in het Nederlands, dus in ons schrift, laten lezen en vertalen. Volgens deze opvatting zouden wij allen ook Chinees of Russisch schrift moeten kunnen lezen.

Wij vinden het 't best om AFAKA door middel van zijn schrift voor zich zelf te laten spreken. Daarvoor geven wij hier, fotografisch gereproduceerd, de geschriften van AFAKA volgens de copie van Pater Morssink, met transcriptie en vertalingen in het Nederlands. Deze werden gelezen en gecorrigeerd door Pater C. Coppelmans, CssR, en door Ds. A. J. Axwijk van de Evangelische Broedergemeente, die beiden jarenlang in aanraking waren met de Aucaners. Fouten blijven vanzelfsprekend voor onze verantwoording.

Wij betuigen hier onze hartelijke dank aan beide heren voor hun medewerking. En bovenal onze erkentelijkheid aan Monseigneur St. KUYPERS voor zijn welwillende vergunning gebruik te maken van dit materiaal.

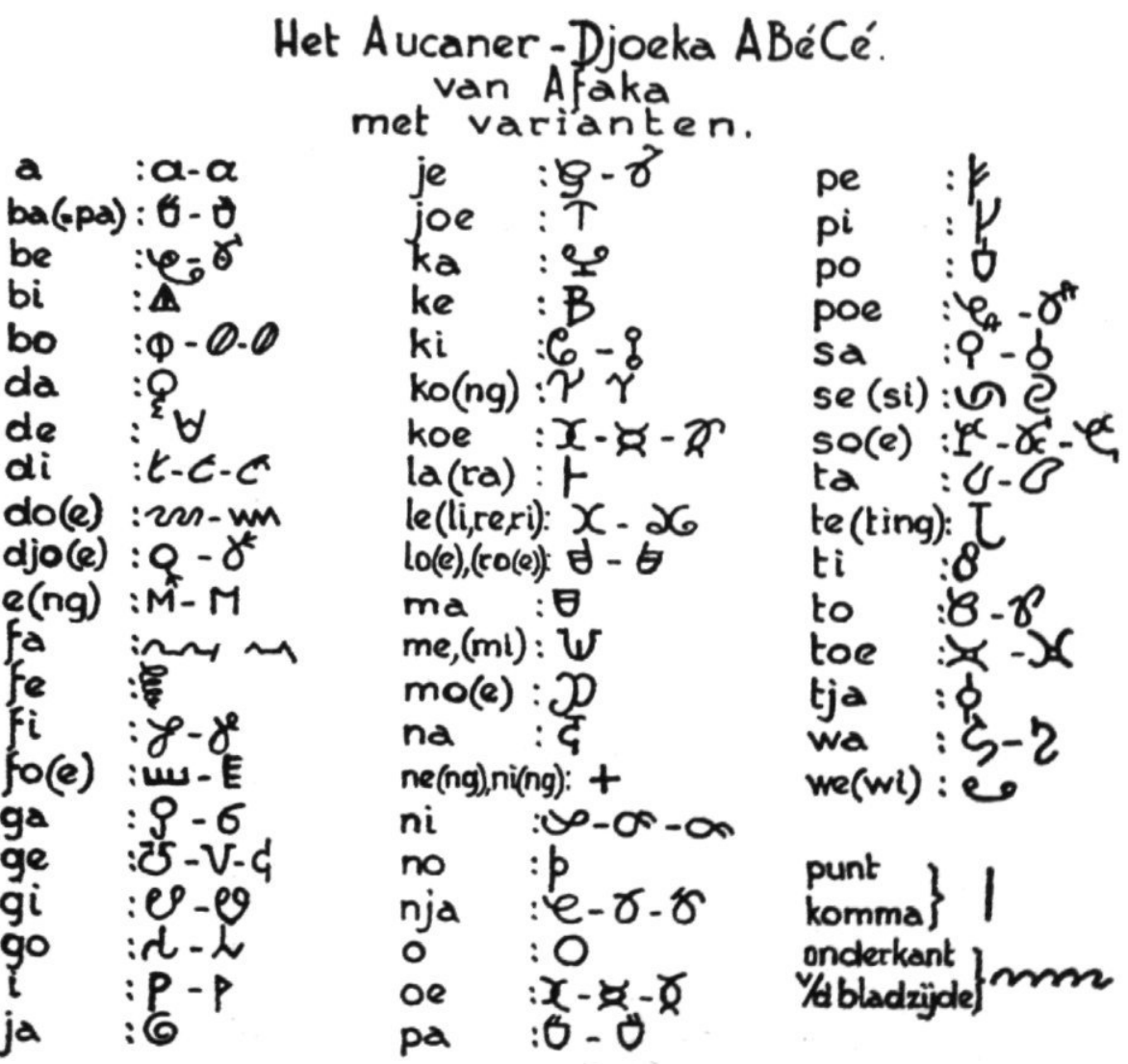


Patili Moloesi bara

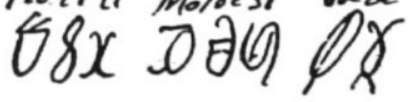

DRUKKERIJ $\nabla / h$ R. K. JONGENSWEESHUIS, Tilburg.

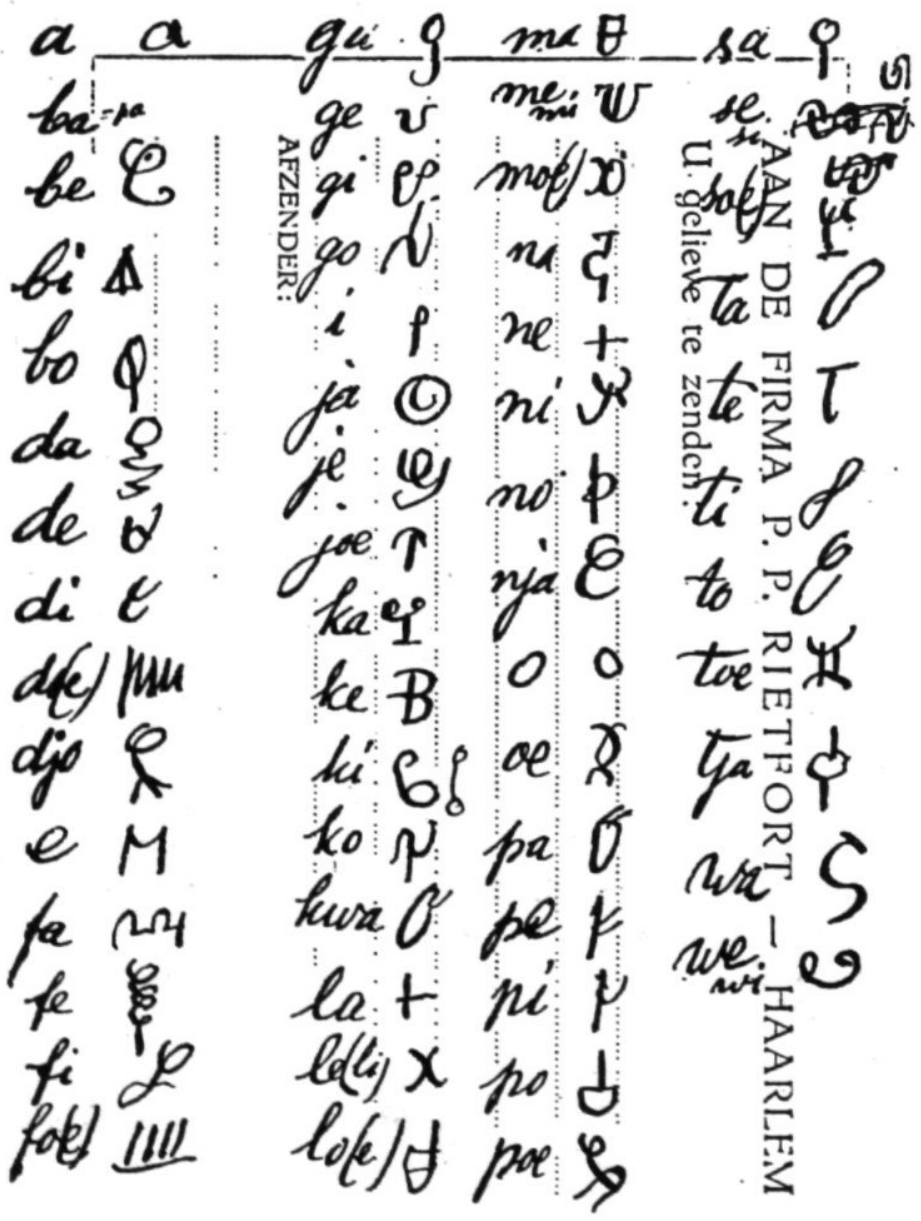


Tenslotte wijzen wij er, misschien ten overvloede op, dat onze tekstinterpretatie en -vertaling een onvolmaakte is en wijd openstaat voor verbeteringen.

\section{PATERI MOROSI BOEKOE}

Het Boek van Pater Morssink

Een aantekenboekje met blauwpapieren omslag, $16 \$ \times 10 \mathrm{~cm}$, afkomstig uit het bisschoppelijk archief te Paramaribo, thans zich bevindende in de bibliotheek van het Ministerie van Onderwijs, Kunsten en Wetenschappen in Den Haag. - Het bevat 56 bladzijden gelinieerd papier, waarvan er 34 zijn beschreven met het Djoeka-schrift van AFAKA. - De meeste bladzijden zijn genummerd, waarbij 7,8 , 19 en 20 werden overgeslagen; 34 en 36 zijn blanco, evenals de bladzijden boven de 40 . Los erbij gevoegd is een bestelkaart met het alfabet.

De bladzijden $21 \mathrm{t} / \mathrm{m}_{4}$ o (dus zonder 34 en 36 ), bevatten

\section{Afschriften van Teksten van Afaka}

soms door tussenkomst van Dr. C. Bonne of ABENA ter hand gesteld aan Pater F. Morssink CssR, in de jaren I917 en 1918.

Het schrift op deze bladzijden wordt, samen met dat op het etiket en de bestelkaart, hierbij fotografisch gereproduceerd - naar opnamen welke, door bemiddeling van de Secretaris Eindredactie N.W.I.G., op het Zoölogisch Laboratorium van de Rijksuniversiteit te Utrecht werden vervaardigd. Een serie afdrukken van de volledige tekst van dit 'Pateri Morosi boekoe' werd aan het Surinaams Museum te Paramaribo ten geschenke gegeven; de negatieven hiervan bevinden zich in de Koninklijke Bibliotheek te 's-Gravenhage.

De inhoud van het boekje is verder:

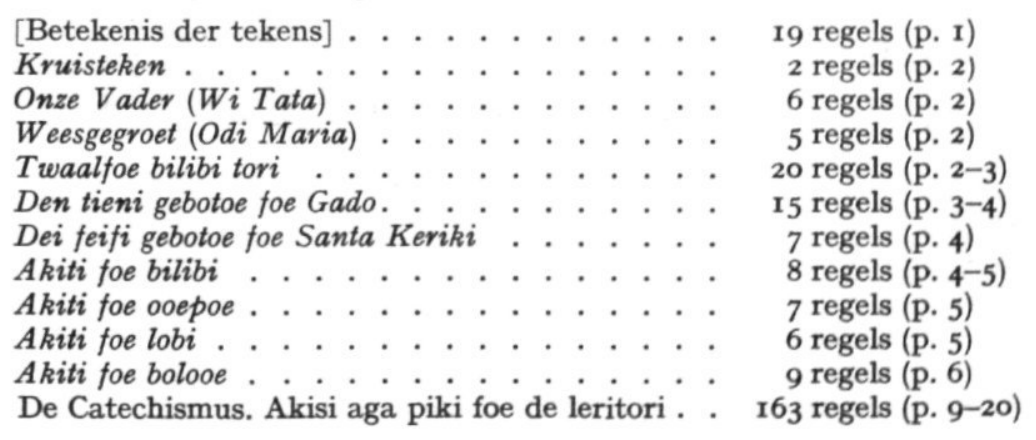




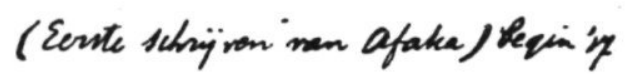

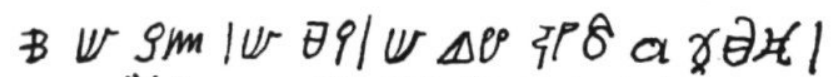

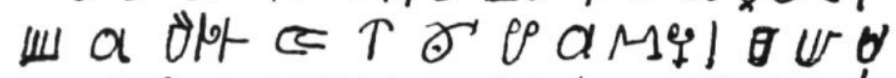

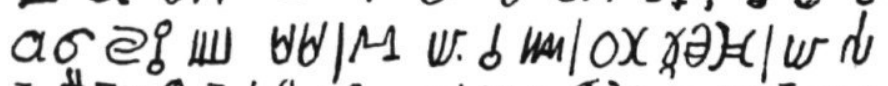

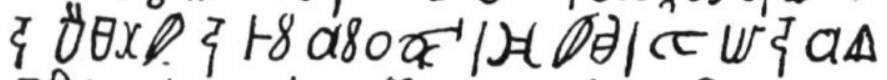

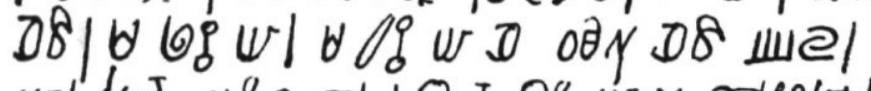

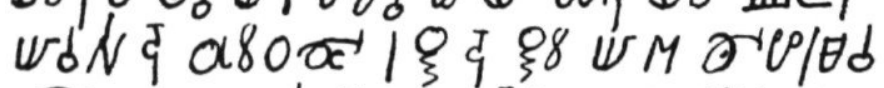

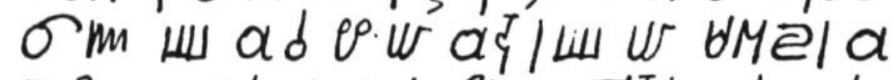

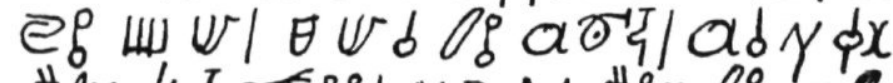

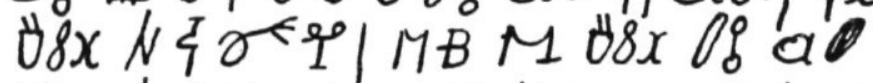
eq/

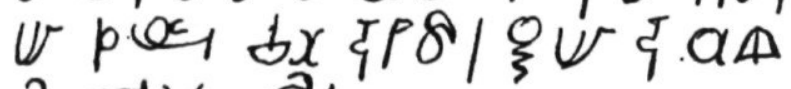
$\theta$ बर्त

(Copie v.'t verhacit, dal afaha selt mij

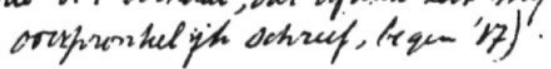

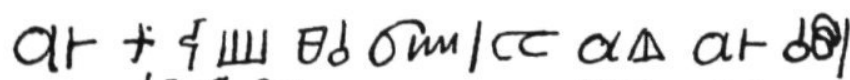
$\alpha \cup B N \theta V \gamma^{A}|\alpha W B=b \theta| a \& x a$

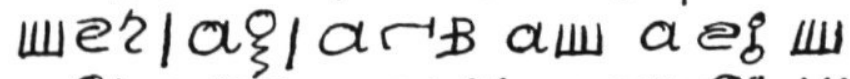
aई।

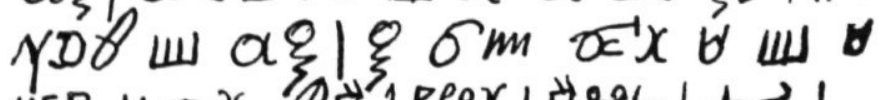
UB $\forall$ त्Cx DU

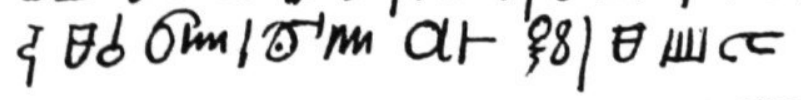


$2 I$

\author{
(Eerste schrijven van Afaka) begin 'I7
}

I ke mi gadoe, mi masa, mi bigi na ini a koeroetoe, foe a papira di joe be gi afaka, ma mi de aga siki foe dede, fa mi sadoe, oli koeroetoe, mi go na pamaribo na lati ati oso, toe bolo, di mi na abi 5 moni, de jaki mi, de taki mi moe oroko moni fosi, mi sa go na ati oso, da na dati mi e begi, masa gadoe foe a sa gi mi ana, foe mi de-esi, a siki foe mi, ma mi sa taki abena, a sa kong tjari patiri go na djoeka, eke fa patiri taki a boeng

ro gi wi, ma mi de aga pe na mi ede, ala mi noso pori na ini, da mi na abi losoetoe toe.

\author{
(Copie v. 't verhaal, dat Afaka zelf mij
} oorspronkelijk schreef, begin 'I7)

a la ning foe masa gadoe, di abi ala sanni,

I5 a mike golontapoe, a mike toe sama, a kali a fosiwang, ada, a teke afoe [gelezen: afoe foe] asiking foe ada, a mike di foe toe a kali dati eva kongmoto foe ada, da gadoe sori de foe de mike de diri boeba, igiri, bakara, ningge,

20 na masa gadoe, be doe ala dati, ma foe di

I Ach, mijn God, mijn Heer, ik begin met de zaak van het papier, dat Gij aan Afaka hebt gegeven, maar ik was doodziek. Hoe zal ik vergadering beleggen. Ik ga naar Paramaribo, naar Lands Ziekenhuis, twee keren, omdat ik geen

5 geld heb, jagen ze me weg. Ze zeggen dat ik eerst geld moet werken voordat ik in het ziekenhuis zal gaan. Daarom bid ik de Heer God, dat Hij mij zal helpen om te genezen die ziekte van mij. Maar ik zal Abena zeggen, dat hij zal komen brengen Pater naar de Tapanahoni. Zo als Pater zegt [is] het goed

ro voor ons. Maar ik heb pijn aan het hoofd. Mijn gehele neus van binnen is bedorven. En dan heb ik ook nergens lust in.

In de naam van de Heer God, die alle dingen heeft.

I5 Hij maakte de aarde. Hij maakte twee mensen. Hij noemde de eerste Adam. Hij nam iets van het lichaam van Adam. Hij maakte de tweede. Hij noemde die Eva, komende uit Adam. Dan wees God hun om te maken de drie huiden, Indianen, Blanken, Negers.

20 De Heer God heeft dit alles gedaan. Maar toen later 


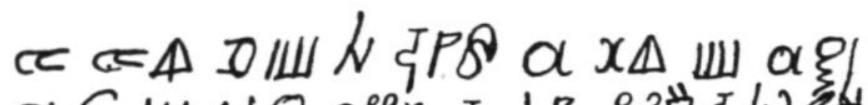

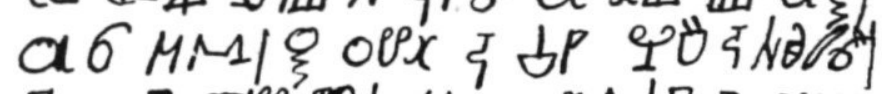

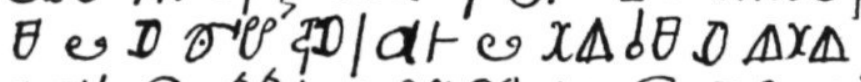

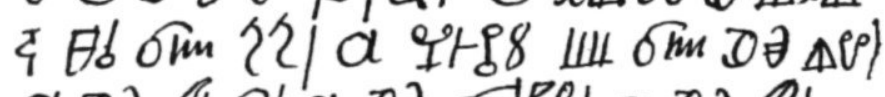
a Da OF $6 / \alpha$ D MSe T $\Delta x \Delta$ द om I Td ox $2 e+\rho$

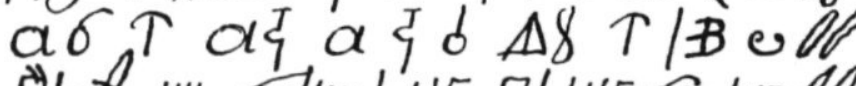

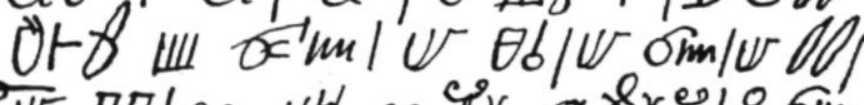

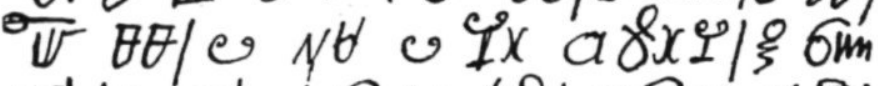

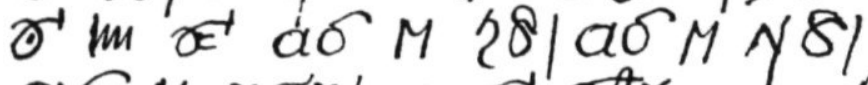

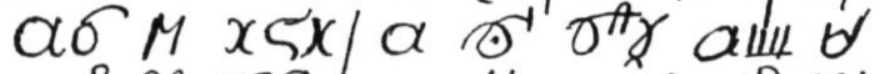

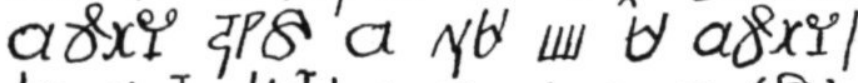

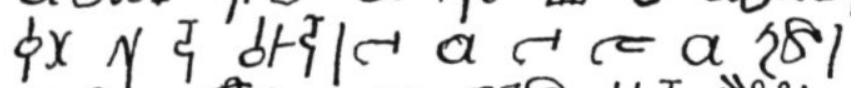

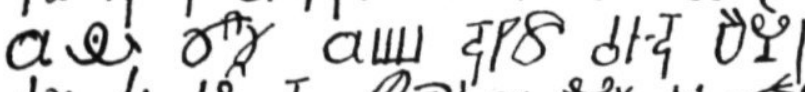

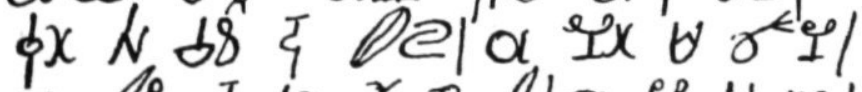
a

$\xi$ a $20 \mathrm{e}+\delta / 2$ a Ix $v$ hese $v$ kf a of $w$ arixe c $b$ द de $v D N d$

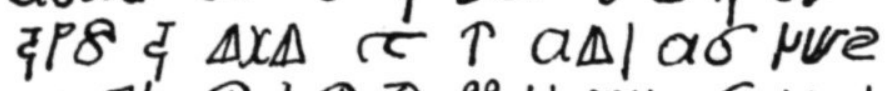

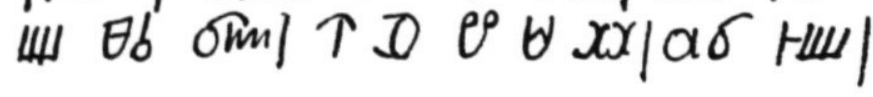


22

I didibi mofo go na ini a libi foe ada, aga eva, da ogiri na poi kaba na gorontapoe, ma wi moe begi namo, ala wi libisama moe bilibi na masa gadoe wang wang, a karakiti foe gadoe moro bigi,

5 a moro taraga, a moro soeiti, a moro boeng, efi joe bilibi na gadoe, joe sa oli wang sineki aga joe ana a no sa biti joe, ke mi tata. palati foe soendoe, mi masa, mi gadoe, mi tata

mi mama, wi konde wi kali afilika, da gadoe

ro be doe so aga eng wanni, aga eng konni, aga eng leri, a be poe-oe afoe de [leri = ligeri = regeling, bestuur] afilika na ini a konde foe de afilika, tjari kong na sarana, te a ting di a wanni, a be poe-oe afoe na ini sarana baka,

I 5 tjari go poti na boesi, a kari de djoeka. a taki na ja koemoeta, a gi de libi, da a ta wang boe pisi langa, da a kari de pilisitisi de piki a taki de afilika di de na boesi de moe kong santa

20 na ini na bilibi di joe abi, aga pimisi foe masa gadoe, joe moe gi de leri, aga lafoe,

I des duivels mond kwam in het leven van Adam en Eva. Het kwaad kan niet ophouden op aarde. Maar wij moeten voortdurend bidden, alle wij mensen moeten geloven in God de Heer alleen. De kracht van God is groter, $5 \mathrm{ze}$ is sterker, ze is zoeter, ze is beter.

Als ge in God gelooft, kunt ge een slang vastpakken met uw hand, ze zal u niet bijten. Ach, mijn Vader. Laat af van de zonde, mijn Heer, mijn God, mijn Vader.

Mijn moeder, ons land noemen wij Afrika. Toen heeft God ro aldus gedaan met Zijn wil, met Zijn kunde,

Zijn beschikking. Hij heeft weggenomen een gedeelte [van] de Afrikanen van uit het land van de Afrikanen [en] gebracht naar Suriname. Ten tijde dat $\mathrm{Hij}$ wilde heeft $\mathrm{Hij}$ wederom een gedeelte uit Suriname weggenomen

I5 en overgebracht naar het bos. Hij noemde hen Djoeka's.

Hij zeide: Hier moet je blijven. Hij gaf hun leven[sonderhoud]. En zo duurde het een lange tijd. Toen riep $\mathrm{Hij}$ de priesters. Ze luisterden. Hij zeide: Die Afrikanen die in het bos zijn moeten geheiligd 20 worden in het geloof dat gij bezit. Met vergunning van de Heer God moet gij hun lering geven - Bij [hun] lachen, 


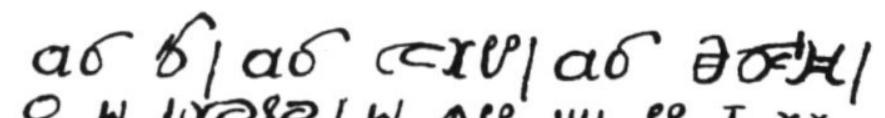

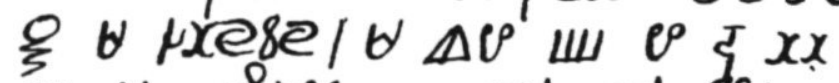

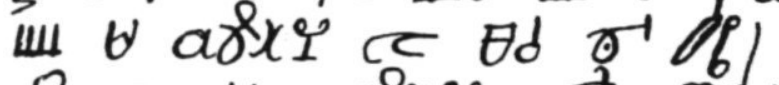

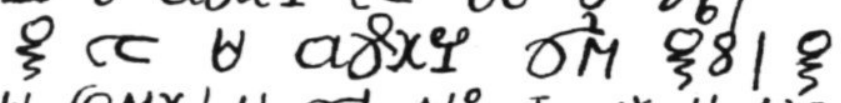

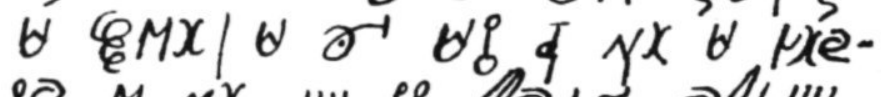

se $M y^{x}$ min ip be+c altill

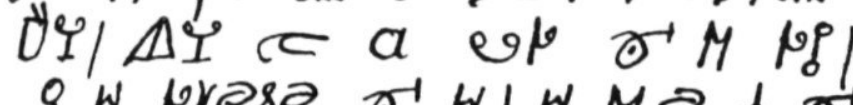

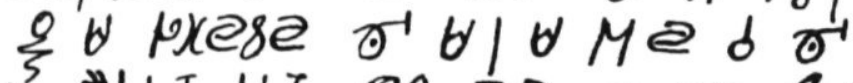

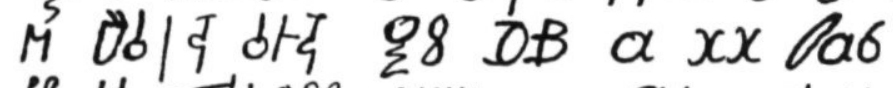

U $b$ व

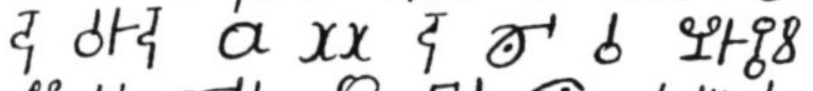

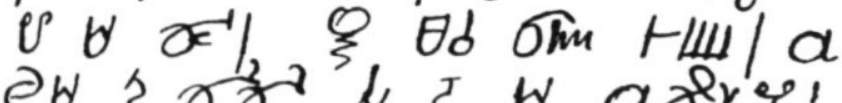

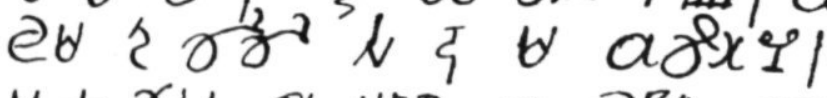

$M+\gamma_{b l}$ a UB a EPA CNM

a k a ix M Xoll a lop/ a po

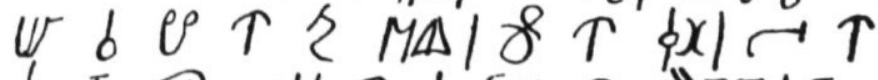

L द Omple $T d \xi$

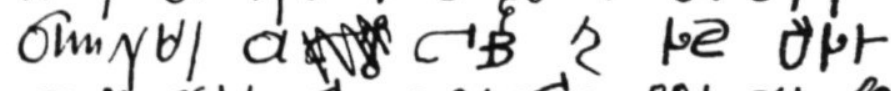

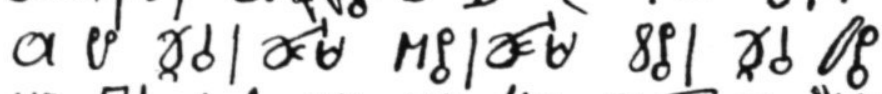

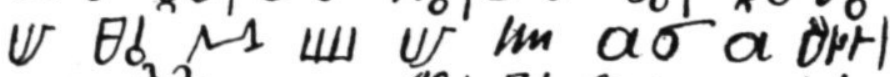

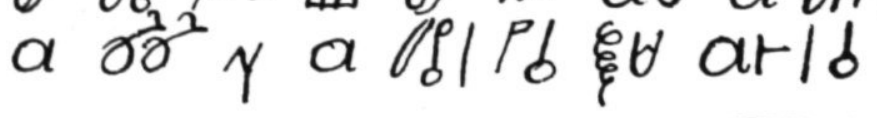


I aga njang, aga dirigi, aga losoetoe, da de pirisitisi, de bigi foe gi na leri foe de afilika di masa be taki, da di de afilika to-e dati, da

5 de fe-ele, de be deki na konni de pirisitisi eng konni toe gi boesiningge sitarafoe baka, bika di a wipi be e piki, da de pirisitisi be de, de e si sa be e masa, na sarana dati moeke a leri taaga

ıo gi de so, bika efoe wi ala be de na sarana a leri na be sa karakiti gi de so, da masa gadoe lafoe, a side wang jeje go na de afilika, a ning oesa, a mike a siibi dipi,

I5 a go a kari eng oesa, a piki, a taki mi sa gi joe wang ebi, fi joe tjari, te joe go na gadoe konde joe sa fede joe paima, na gadoe konde, a teke wang pisi papira a gi oesa, sonde eki, sonde tiki, oesa taki

$20 \mathrm{mi}$ masa, fa foe mi doe aga a papira a jeje kong a taki, i sa fende ala, sa

I bij [hun] eten, bij [hun] drinken, bij [hun] genoegens. Dan beginnen de priesters de lering te geven aan de Afrikanen zoals de Heer gezegd had. Dan verwerpen de Afrikanen dat. Dan

5 zij vrezen. Zij denken de priesters bedriegen met list de bosnegers om ze weer in slavernij te brengen. Want toen de zweep sprak, waren de priesters er [ook]. Zij zien wie in Suriname baas was Daarom was de lering ook moeilijk voor hen zelf.

Io Want als wij allen in Suriname geweest waren, [dus nog niet in het bos] dan zou de lering voor hen ook niet zoo moeilijk zijn geweest.

Toen heeft de Heer God gelachen. Hij zond een geest naar die Afrikaan genaamd Oesa ${ }^{1}$. Hij bracht hem in diepe slaap.

I5 Hij ging en riep hem, Oesa, die luisterde. Hij zeide: Ik zal U een last te dragen geven, wanneer gij naar Gods land gaat zult gij uw loon vinden in Gods land. Hij nam een blad papier en gaf dit aan Oesa, zonder inkt, zonder [schrijf]stift. Oesa zeide:

20 Mijn Heer, wat moet ik doen met dit papier? De geest kwam en zeide: Gij zult alles krijgen

1 Afaka noemt zichzelf soms Oesa, soms Atoemisi. 


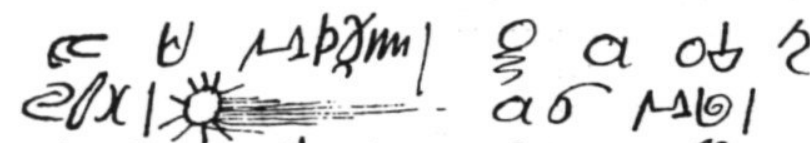

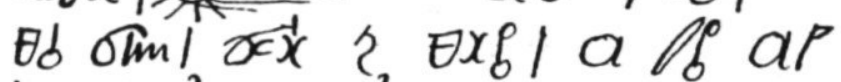

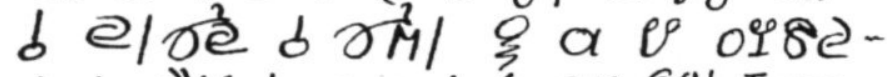

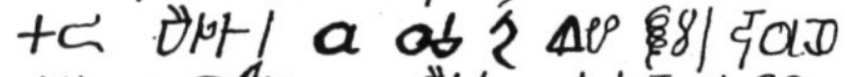

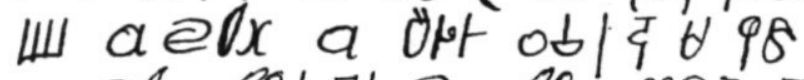

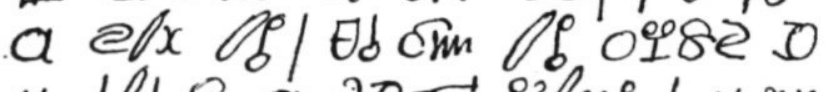
Y d 01 \& a - oyse z dl xa ce e DaAl $a \sigma$ HIII a a pxex/ao xekpl 山

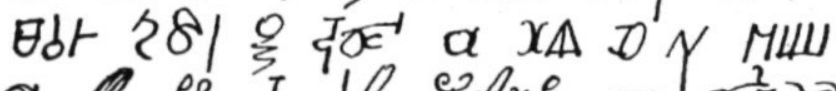

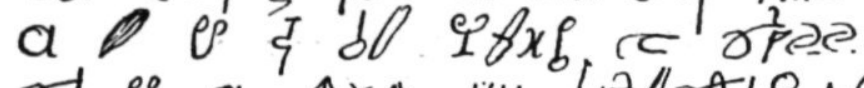

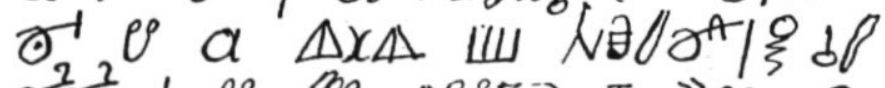
Jơ o es a ys w

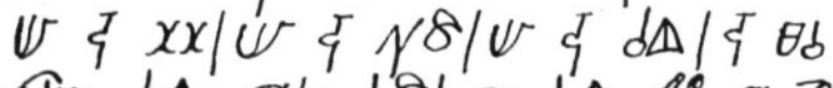
oim $d \Delta$ at $b 8 /$ a $b \Delta \quad 0 b$ a p zota otor un es $x \Delta / a$ - $e^{p}$ testal B e OP e $\theta$ bl e om at Deta b8 88 ? 
24

I di de fanooedoe, da a opo wang sitarie, aga faja, masa gadoe sori wang mariki, a taki ai sa si, jesi sa je-e, da a gi okanisi

5 ningge papira, a opo wang bigi feti, na a moeng foe a sitari a papira opo, na de sani a sitari taki, masa gadoe taki okanisi moe kong santa, da a romoesoe katoliki sa kong leri de okanisi na santa libi di wi moe abi,

ro aga lafoe, aga pirisiri, aga resipeki, foe masa gadoe, da a libi sa kong eke fa masara wanni, da na so a libi moe kong efoe a boeng gi na santa katoliki di jeisisi be gi a biribi foe gorontapoe, da santa

I 5 jeje sa gi tangi bikaisi na bakara gadoe be gi a konni foe gorontapoe, mi na leri, mi na konni, mi na sabi, na masa gadoe sabi ala sanni, a sabi taki a moe gi loweningge papira foe wi libi a

20 boen gi loweningge, ke wi tata wi masa, wi gadoe, ala boesiningge poti kini na

I wat nodig is. Toen liet $\mathrm{Hij}$ een ster verschijnen, met vuur. 1 De Heer toonde een teken. Hij zeide: Ogen zullen zien. Oren zullen horen. Dan geeft Hij de Aukaners 5 papier [schrift]. Hij begint een grote oorlog. In de maand van de ster ontstond het schrift. Die dingen zeide de ster. De Heer God zeide de Aukaners moeten worden geheiligd. Dan zal de Rooms-Katholieke [Kerk] komen leren de Aukaners het gewijde leven dat wij moeten hebben.

ro Met lachen, met plezier, met respekt voor de Heer God. Dan zal het leven worden zo als de Heer wil. En zo moet het leven worden als het goed is voor de heilige Katholieke [Kerk], aan welke Jezus gaf het geloof voor de wereld. De Heilige Geest zal danken.

I5 Want aan de blanken gaf God de kunde van de wereld.

Ik ben niet geleerd. Ik heb geen kunde. Ik weet niets. De Heer God weet alle dingen. Hij weet dat $\mathrm{Hij}$ de weggelopen negers schrift moet geven voor ons leven.

20 De weggelopen negers vinden het goed. Ach, onze Vader, onze Heer, onze God. Alle bosnegers knielen op de grond,

1 Deze ster is de komeet van Halley, die in I91o zichtbaar was. 

25

I doti, wi opo wi ede na tapoe, ma wi ai de tapoetapoe, wi ana de tapoetapoe, opo wi wi tata wi begi, masa gadoe, aga pirimisi aga resipeki, joe

5 wanni moesoe de na grontapoe, gi joe leri so-eke fa a fiti, mi tata joe gi mi a sikolo oso foe mi moke, ke ma mi na abi oedoe, mi na abi palanga, mi na abi oewiri, ke mi tata wang finga poi dirigi

Io okoro, okanisi kisi papira, de sa kisi leri de sa kisi konni, de sa kisi sabi, wi sa libi na santa libi na kirifasi sa kong, te na leti dei sa kong wi ala sa de na a wang pasi e go, na a leti konde,

I5 aga lafoe, aga sigi, aga pirisiri, na so amakiti tata taki, wi moe libi aga leri, da sama de di taki na boeng sani, sama de di taki na soso sani me e doe, te na mi famiri de jaki me de taki $20 \mathrm{mi}$ konni toemisi, da mi be wanni fika a papira (cfr. infra $p . \quad$ ), ma abena, bilibi

I wij richten ons hoofd naar boven, maar onze ogen zijn gesloten, onze handen zijn gesloten. Verhef ons. Wij bidden onze Vader, Here God, met [Uw] goedvinden, met eerbied. Uw wil

5 geschiede op aarde. Geef Uw lering gelijk het past, mijn Vader. Gij draagt mij op de school te bouwen. Maar ik heb geen hout, ik heb geen planken, ik heb geen bladeren [dakbedekking]. Ach, mijn Vader, kan een vinger drinken

Io oker[soep]? De Aukaners krijgen schrift. We zullen onderwijs krijgen. Ze zullen kunde krijgen. Ze zullen weten. Wij zullen het heilige leven leven. De verlichting zal komen. Als de juiste dag zal komen zullen we allen op éen weg voortgaan, naar het ware land,

I5 met lachen, met zingen, met vreugde. Zo zegt de Almachtige Vader. Wij moeten leven met kennis.

Dan, er zijn mensen die zeggen het is een goed ding, mensen die zeggen het is onzin wat ik doe, zodat mijn familie mij heeft uitgestoten. Ze zeggen

20 dat ik te knap ben. Toen heb ik willen laten [wegdoen] het schrift (cfr. infra p. 229). Maar Abena gelooft 
26

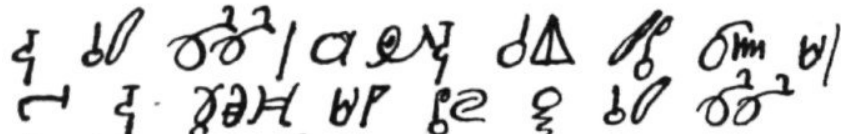

$$
\begin{aligned}
& \text { b ep } M \text { Dep/Ar at } \forall \text { Mux } \\
& \text { Iil) } a \sigma^{-1} y \text { r } \Delta x \Delta M \forall \sigma
\end{aligned}
$$

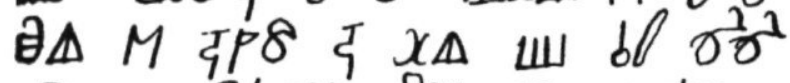

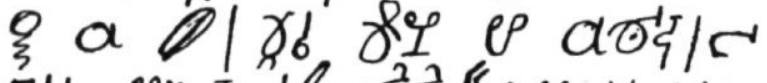

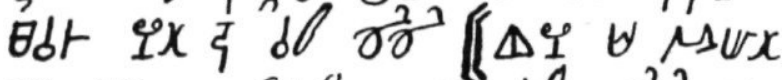

$$
\begin{aligned}
& \text { III } \psi \text { ox } 8+8 a \sigma^{5} d 0 \text { के } y
\end{aligned}
$$

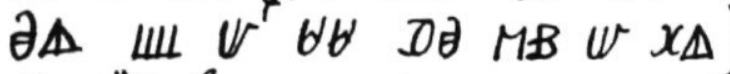

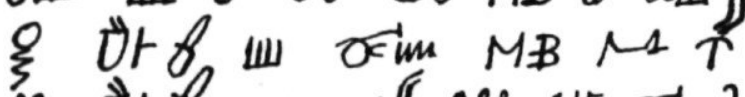

$$
\begin{aligned}
& \text { if }
\end{aligned}
$$

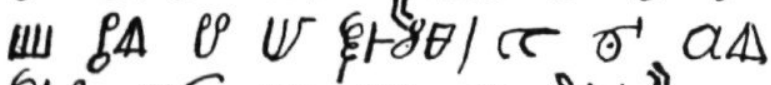

$$
\begin{aligned}
& \text { क्कt-8 aर } w \text { w a }
\end{aligned}
$$

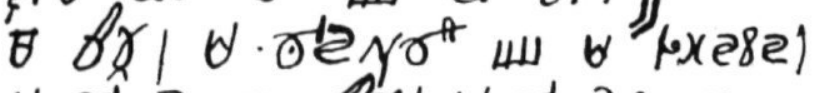

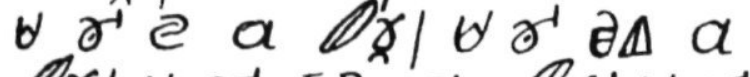

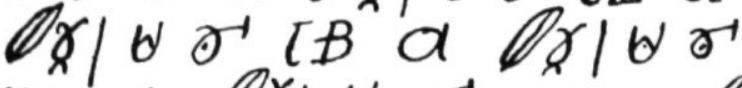

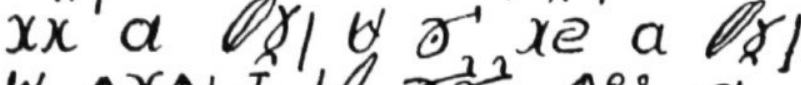

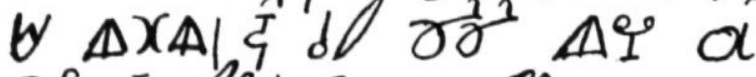

$$
\begin{aligned}
& \text { อf द } 881 . \theta \text { a DA } \\
& \text { द या }
\end{aligned}
$$


26

I na santa jeje, abena sabi taki gadoe de te na koeroetoe dei kisi da santa jeje sa gi e taki, bika ala de famiri foe abena de be bilibi e de be

5 lobi e na ini na libi foe santa jeje dang a boeng. Oesa fika gi abena, te masara kari na santa jeje [ [bika de famiri foe mi oli ferati aga santa jeje de lobi foe mi dede moro eke mi libi]]

ro da parato foe sondoe eke fa joe gi parato alating [ [bika me be lo foe kibi gi mi feratimang, di be ala ferati aga $\mathrm{mi}$ foe a papira]] ma tokoe, de be si kong boe foe de pirisitisi,

I 5 de be si a boekoe, de be lobi a boekoe, de be teke a boekoe, de be leri a boekoe, de be lesi a boekoe, de bilibi, na santa jeje bika a siking na doti, ma a boro foe ati

20 na foe santa

I de Heilige geest. Abena weet dat God er is. Als de oordeelsdag is aangebroken zal de Heilige Geest hem doen spreken. Want al de verwanten van Abena ze hebben geloofd en ze hebben

5 begeerd [te zijn] in het leven van de Heilige Geest. Omdat zijn verwanten in het goede verblijven, laat Oesa het over aan Abena, totdat de Heer de Heilige Geest roept. [[Want de verwanten van mij zijn de Heilige Geest vijandig gezind. Ze wensen mij liever dood dan levend.]]

Io Daarom, vergiffenis voor zonde, zo als U altijd vergiffenis geeft. [[Want ik ben gevlucht om mij te verbergen voor mijn vijanden, die allen vijandig waren tegen mij vanwege het schrift.]] Maar toch, ze hebben goeds zien komen van de priesters.

I5 Ze hebben het schrift gezien, ze hielden van het schrift, ze hebben het schrift aangenomen, ze hebben het schrift geleerd, ze hebben het schrift gelezen. Ze geloven de Heilige Geest. Want het lichaam is aarde. Maar de adem van het hart [het innerlijke] 20 is om heilig te worden. 


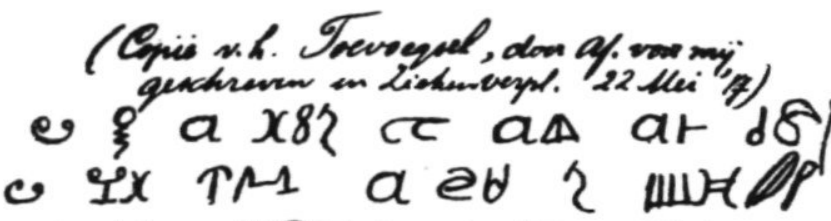

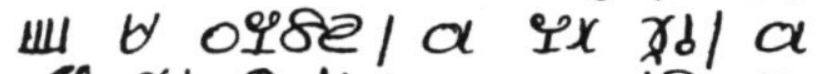
Of रो $T \mathrm{Mm}$ ar d8 $\theta$

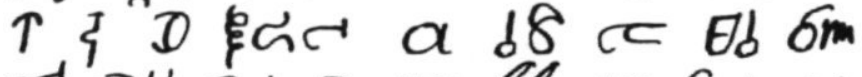

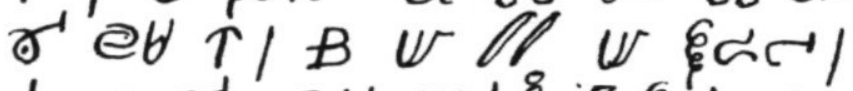

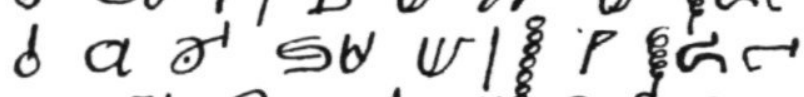
c $\theta d$ om Fed $T$ \& $T x x$

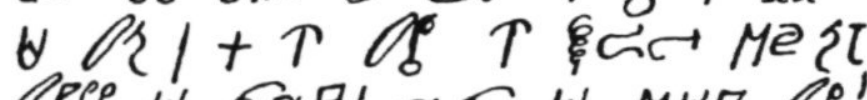

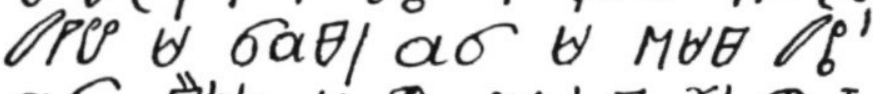

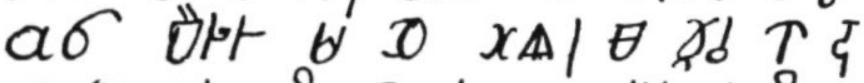
$D$ P MX|MP $T$ d

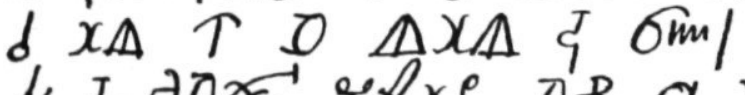

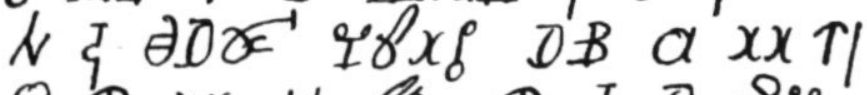

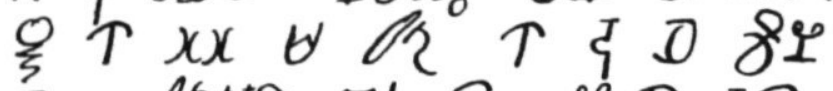
द of

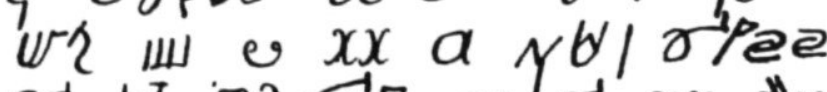
ने we a les द ompol 
27

(Copie v.h. Toevoegsel, door Af. voor mij
geschreven in Ziekenverpl. $22 \mathrm{Mei}$ 'I7)

I we dan a letiwang di abi ala sani,

wi kari joe fa a sinde wang foetoeboi

foe de okanisi, a kari oesa, a

taki oesa joe e doe ala sani ma

5 joe na moe fegete a sani di masa gadoe

be side joe, ke mi tata me fegete,

sa a be side mi. i figete,

di masa gadoe be side joe fi joe leri

de tawang, ne joe taki joe fegete esi wanting

Io taigi de gaaman, aga de edeman, taki

aga papira de moe libi, ma oesa joe na

moe fe-ele, efi joe sa dede efi joe

sa libi joe moe bilibi na gadoe,

go na romoesoe katoliki moeke a leri joe,

15 da joe leri de tawang joe na moe fika

na otofini masa gadoe gi joe, naga

mi wang foe wi leri a konde, jeisisi

be pina moro soema a be leri papira

fosi a gowe na gadoe konde

I Welnu dan, Gerechte, die alle dingen hebt.

Wij roepen $\mathrm{U}$ opdat $\mathrm{Gij}$ zendt een knecht

naar de Aukaners. Hij roept Oesa. Hij

zegt: Oesa, je doet alles, maar

5 je moet niet vergeten de opdracht die God, de Heer,

je gezonden heeft [uit te voeren]. Ach, mijn Vader, ik heb vergeten

wat $\mathrm{Gij}$ mij gezonden hebt [te doen]. Heb je vergeten

dat God, de Heer, je opgedragen heeft te leren

de anderen? Jij, je zegt je vergeet gauw in eens.

ıo Zeg aan de Granman, en aan de hoofden, dat

zij met het schrift moeten leven. Maar, Oesa,

je moet niet bang zijn. Of je zult sterven of dat je

zult leven, je moet in God geloven.

Ga naar de Rooms-Katholieke [Kerk] en laat ze je onderwijzen.

I5 En dan leer je de anderen. Je moet niet opgeven de levenswijsheid die God, de Heer, gaf. Aan jou en mij alleen, opdat wij het land onderwijzen. Jezus heeft geleden bovenmenselijk. Hij heeft schrift geleerd voordat $\mathrm{Hij}$ weg ging naar Gods land. 


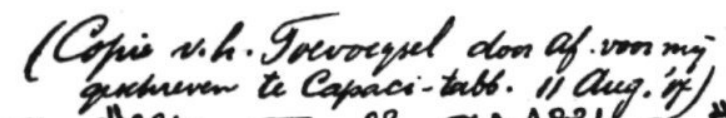

$$
\begin{aligned}
& \text { a tैr ce } P \text { arsil a tor } \\
& \text { I eral a of } \rightarrow \text { ar } k \theta 0 \text { क } \\
& \text { dA } 2 \text { om } \xi \text { ? d } \theta \text { ret d } Y \\
& \text { सिए } v \text { ? }
\end{aligned}
$$

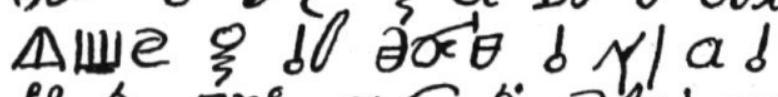

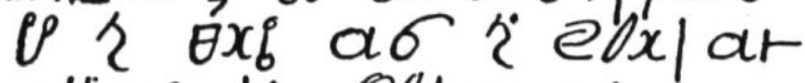

$$
\begin{aligned}
& y b^{2} D \text { d } \$ 8 / m \text { स } a y
\end{aligned}
$$

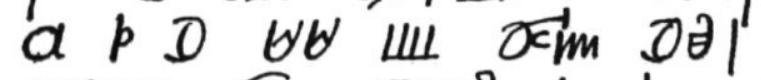

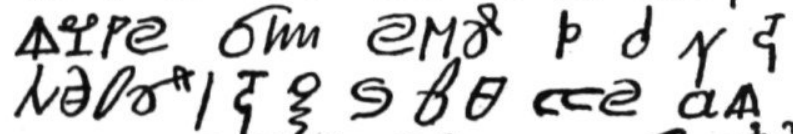

$$
\begin{aligned}
& \text { at } 858 \text { दP8 } \$ 8 \text { at }{ }^{2}
\end{aligned}
$$

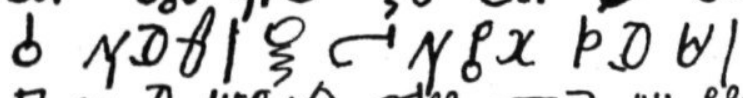

$$
\begin{aligned}
& \theta \text { o }
\end{aligned}
$$

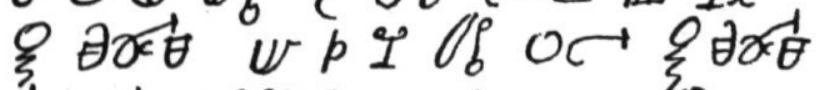

$$
\begin{aligned}
& \text { o N } 1 \text { Aipe w } p \text { aA }
\end{aligned}
$$

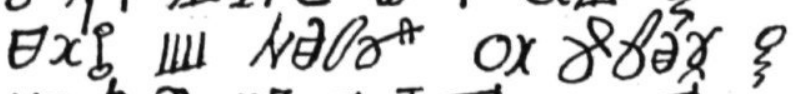

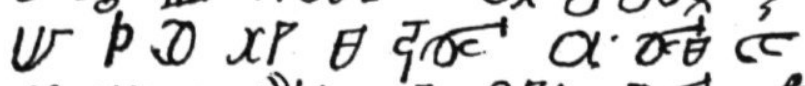

$$
\begin{aligned}
& \text { os w a Obt \& URA द⿱乛龰 a Bs, }
\end{aligned}
$$


28

(Copie v.h. Toevoegsel door Af. voor mij geschreven te Capaci-tabb. II Aug. 'I7)

I a bakara di gi afaka, a papira

na siibi, a taki te ala gorontapoe

sabi wang gadoe da wang santa losoeman sa kong

losoe de boe wang da a keti de ogiriwang,

5 bifosi da santa losoeman sa kong, a sa

gi wang mariki aga wang sitari, ala

konde moe sabi dati, foe te a kong

a no moe dede foe sondoe moro,

bikaisi gadoe siefi no sa kong na

ro gorontapoe, na da setiman disi abi

ala makiti naini dati ala boeng jeje

sa koemoto, da te konkiri no moe de,

ma wi moe meki wang begi disi foe kari

da losoeman mi no ka taki oting da losoeman

I5 sa kong, bikasi mi no abi da

mariki foe gorontapoe oli fitorooe da

mi no moe lei ma naso a soema di

gi mi a papira na sibi naso a taki

I De blanke die Afaka het Papier [schrift] heeft gegeven toen hij sliep, heeft gezegd: Wanneer de gehele wereld één God erkent, dan zal een heilige Verlosser komen om de goeden te verlossen. Hij ketent de bozen.

5 Voordat de Heilige Verlosser zal komen, zal Hij een teken geven met een ster. De gehele wereld moet dit weten, omdat als Hij gekomen is $\mathrm{Hij}$ niet meer moet sterven voor zonden.

Want God zelf zal niet komen op

Io aarde. Die plaatsvervanger heeft

alle macht. Uit Hem zal alle goede geest

voortkomen. Die tijd: kwaadsprekerij moet er niet zijn. Maar wij moeten bidden om te roepen

de Verlosser. Ik kan niet zeggen wanneer de Verlosser

I5 zal komen, want ik heb niet het

teken voor de wereld. Blijf vertrouwen. En

ik moet niet liegen. Maar aldus heeft de mens

die mij in mijn slaap het Papier [schrift] gaf gesproken. 


\section{Copie ust env ander bratis sangit}

a $\triangle P^{\circ}$ WI $a$ O

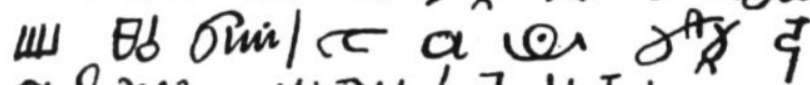

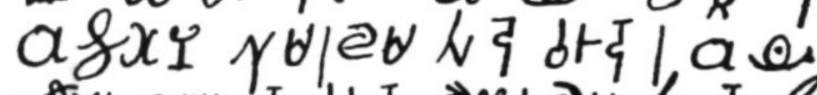

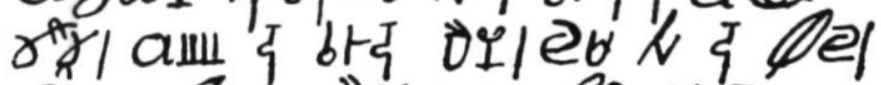

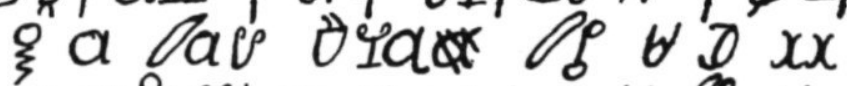

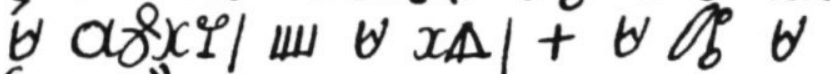
छmx Jia M NX w w fe

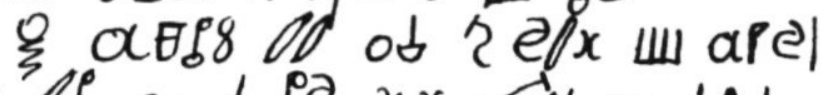

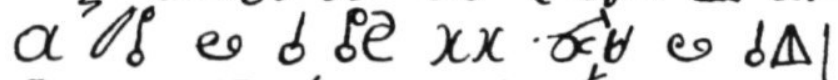

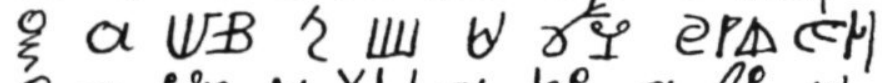

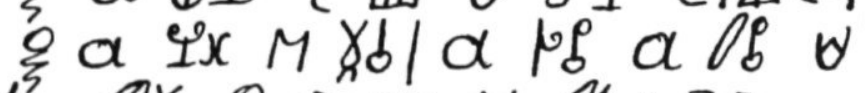

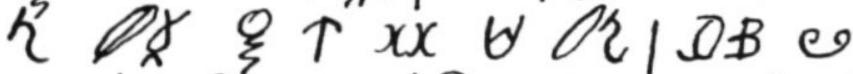
$x \Delta|a r|$ om $28 \mid$ o om d $y$

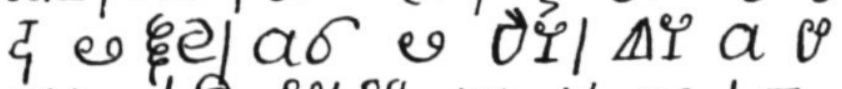

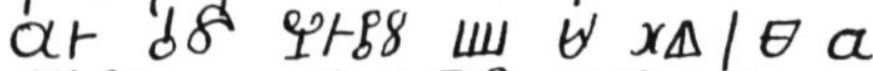
itgs

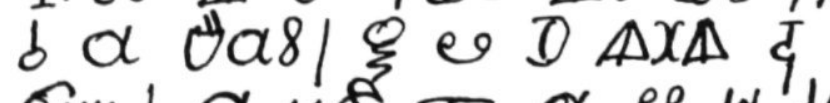

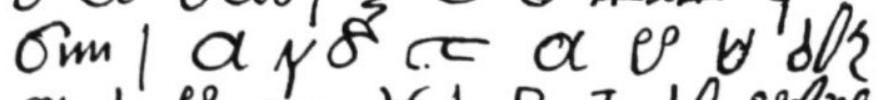

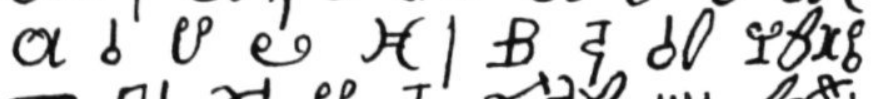

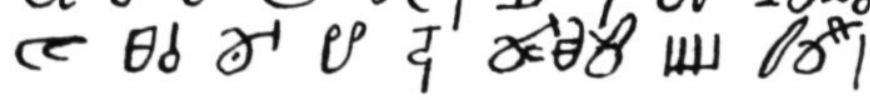


29

\author{
Copie uit een ander boekje van $A f$. \\ mij door Ab. gegeven Aug. 'I8.)
}

I a bigi foe a boekoe foe de afirika foe masa gadoe, di a be soekoe na afirika konde, sibi ge na sarana, a be poeoe, afoe na sarana baka, sibi go na boesi,

5 da a taagi baka a taki de moe leri, de afirika, foe de libi, ning de taki de fe-ele bakaa e kori de foe kisi.

da amakiti tata opo wang sitari foe ai si, a taki wi sa kisi leri soede wi sabi,

Io da a meki wang foe de djoeka siibi dipi, da a kari eng oesa, a piki a taki de wang boekoe, da joe leri de tawang, moke wi libi, aga gadoe wanni, da gadoe sa de na wi fesi, aga wi baka, bika a gi

I5 ala sanni karakiti foe de libi, ma a karakiti foe gadoe, moro bigi moro eke sa a paati, da wi moe bilibi na gadoe, a konni di a gi de santawang a sa gi wi toe, ke na santa katoliki 20 di masa be gi na soeloto foe tapoe,

I Het begin van het verhaal van de Afrikanen van God, de Heer, die Hij heeft gevoerd uit het land van Afrika en gezonden naar Suriname. Hij heeft genomen een gedeelte uit Suriname weder, gezonden naar het bos.

5 Vervolgens zegt Hij de blanken dat ze moeten onderwijzen de Afrikanen opdat ze leven. Toen zeiden ze dat ze bang waren dat de blanken hen zouden bedriegen om ze te pakken.

De Almachtige Vader heeft een ster doen opgaan opdat de ogen zien. Hij zeide wij zullen leren zonder dat we het weten.

Io Toen heeft Hij een van de Djoeka's in diepe slaap gebracht.

Hij riep hem: Oesa. Deze antwoordde. Hij sprak tot hem: Ziehier een schrift, dan leer je de anderen, opdat wij leven volgens Gods wil. Dan zal God zijn voor ons en achter ons, want $\mathrm{Hij}$

I 5 geeft alle dingen kracht om te leven. Maar de kracht van God is groter dan wat $\mathrm{Hij}$ uitdeelt. Daarom moeten wij geloven in God. De kennis die Hij de Heiligen gaf zal Hij ook aan ons geven. Ach, de heilige Katholieke [Kerk] 20 die de Heer heeft gegeven de sleutel van boven, 
3

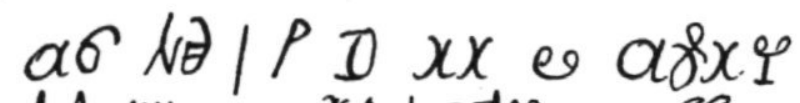

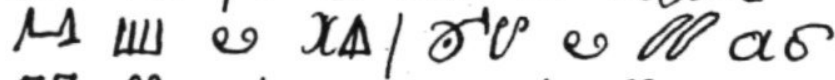

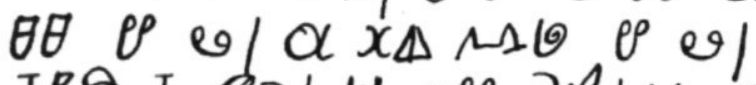

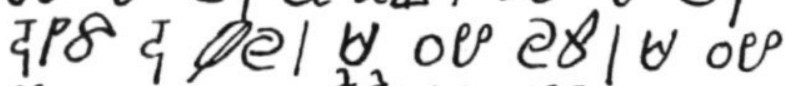

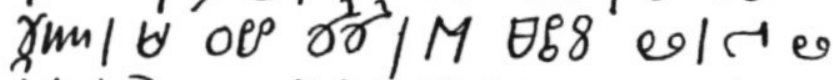

$M$ te es $x \Delta / \theta$ MW es $\Delta x \Delta$

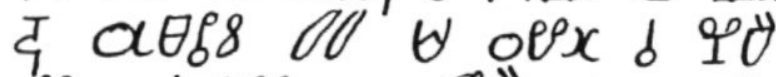

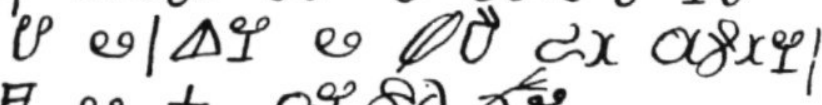

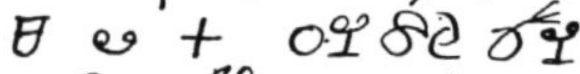

oim Of at $\forall Y^{W} \amalg$ br)t

$20 M x \Delta$ ar ov

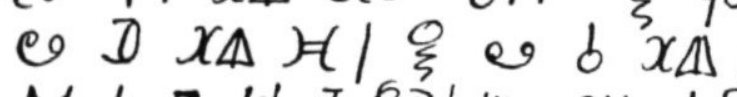

$M+D \theta द$ दो

$B \forall \delta a \theta l$ ar 4 MUt

$\forall$ बठ/ o $0 \Delta x \Delta /\{\xi x 8$ om

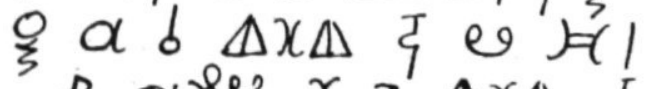

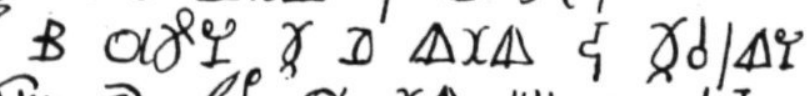

om 2 of a $x \Delta \Delta$ uld es

$+\forall$ a

CB DB $x \Delta /$ \& $W$ U⿻

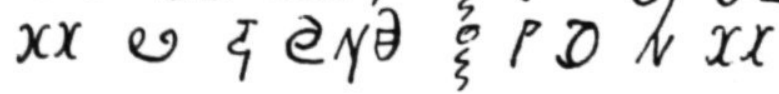


30

I aga gorong, ie moe leri wi afilika fa foe wi libi, begi wi tata aga mama gi wi, a libi faja gi wi, na ini na boesi, de ogi sitong, di ogi 5 oedoe, di ogi jeje, e makiti wi, te wi e lasi wi libi, ma efoe wi bilibi na amakiti tata de ogiri sa kaba gi wi, bika wi boeba geri afirika, ma wi ning okanisi djoeka.

ro gadoe taki ala de konde foe saoetoe wata e libi aga papira da na so wi moe libi toe, da wi sa libi. e ning moe de na fesi, foe ala sanni, ke de gaama, aga de edema, de ba-ala,

I5 de sisa, wi moe bilibi, na da leti gadoe, da a sa bilibi na wi toe.

ke aflika oe moe bilibi na oesa, bika gadoe si taki a libi foe wi pina nede a gi wi a koni foe wi

20 teke moeke libi, da te de bakaa leri wi na sikolo da i moe go leri

I en op aarde, gij moet ons Afrikanen leren hoe wij moeten leven. Bid onze Vader en Moeder voor ons, het levensvuur voor ons.

In het bos, de kwade stenen,

5 de kwade bomen, de kwade geesten houden ons in hun macht, zodat wij ons leven verliezen. Maar als wij geloven in de Almachtige Vader dan zullen de slechte [dingen] ophouden voor ons, want onze huid gelijkt de Afrikaan, maar onze naam is Aukaner Djoeka.

ro God zegt alle landen van het zoute water leven met schrift. Dan moeten wij ook zo leven. Dan zullen wij leven. Zijn naam moet voorgaan voor alle dingen. Ach, de Granmans en de hoofden, de broeders,

I5 de zusters, wij moeten geloven in de ware God, dan zal Hij ook in ons geloven.

Ach, Afrikanen, gij moet Oesa geloven, want God ziet dat ons leven gebrekkig is.

Daarom gaf Hij ons de kunst om

20 het leven [beter] te maken. En als de blanken ons op school leren dan moet gij gaan leren 


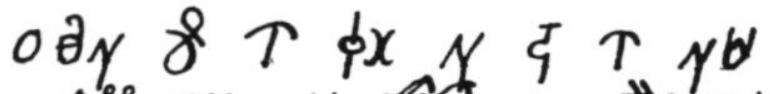

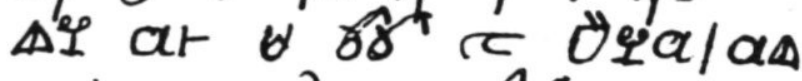

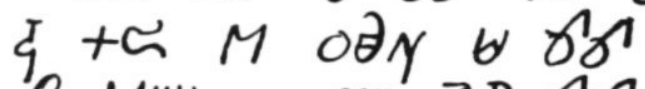

\% Mu山 es $x x$ वB fro of d d

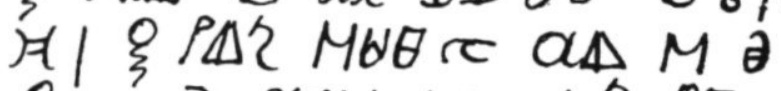

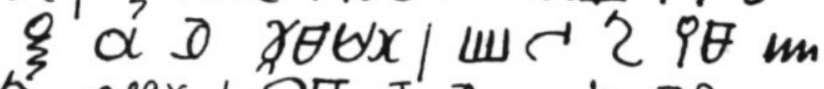

$200 x / 0 \theta \xi D$ ep $0 \theta$

$\forall$ шеत arxy द $\theta_{\Delta} \xi 81$

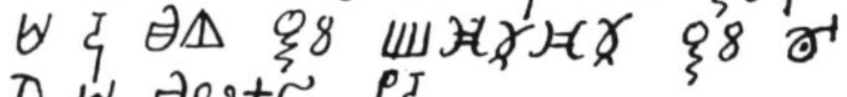

Dष $\theta$ ert

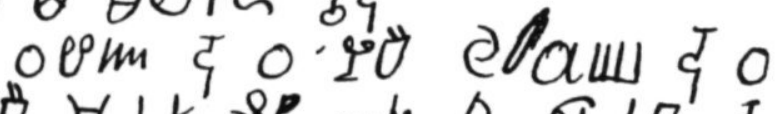
ID A $1 F$ \&P of 2 of d $\theta$ d8 DUW OT DB ellaw or'।

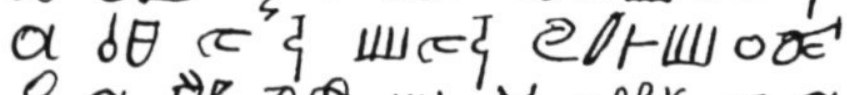
$\xi a . U P D A m$.

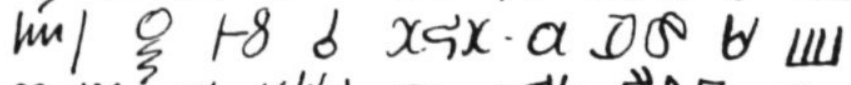

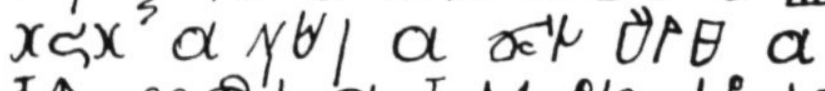

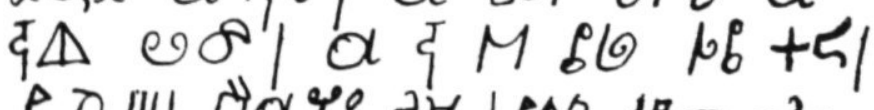

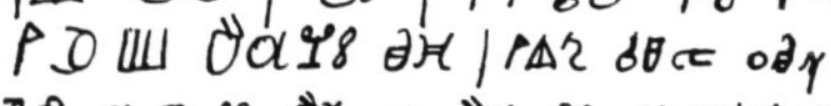

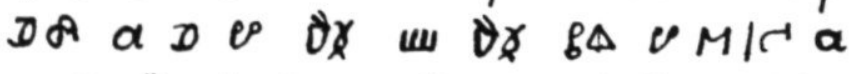
WI dx d T 
$3 I$

I oroko fi joe tjari kong na joe konde

bika ala de njanja di bakaa, abi

na ningge e oroko de njanja

da efoe wi leri moeke njanja wi sa, sabi

5 toe, da ibiwang edemang di abi e lo

da a moe koemanderi, foe te wan sama doe

wan ogri, gaman na moe wipi moro

de fositing afirika na lobi dati,

de na lobi dati foetoeöetoeöe dati be

1o moe de loweningge kina

ogidoe na o kaba sitaafoe na o

kaba toe, pe fei wipi wang garansama na

sato mofo da joe moeke sitaafoe oso,

a sama di na foedina sitarafoe oso

I5 da a pai moni foe e ogiri di a

doe, da lanti sa rigeri, a moni de foe

rigeri a konde, a sopi paiman a

nabi wini, a na e kija piki ningge,

i mofo paakati lotoe, ibiwang sama di oroko

20 moni a moe gi bankoe foe bankoe kibi gi eng, te a

foeka bankoe sa joe a moni gi eng, da te lati

I werken om naar je dorp [de opbrengst] te brengen.

Want al de vruchten die de blanken hebben,

de negers brengen die vruchten voort.

En als wij dan leren vruchten voort te brengen, dan zullen wij het ook

5 Dan moet iedere hoofdman die zijn stamgroep heeft,

kunnen.

dan moet hij optreden. Indien iemand

iets kwaads doet, moet de granman niet meer [laten] geselen.

De Afrikanen van vroeger houden daar niet van.

Ze houden daar beslist niet van. Dat moest

Io taboe wezen, een verbod van de weggelopen negers.

Kwaaddoen zal niet ophouden, straf ook

zal niet ophouden. In plaats van een volwassene te geselen moet gij een huis voor gestraften [gevangenis] maken.

Iemand die niet de gevangenis verdient,

I5 hij betale geld voor het kwaad dat hij

doet [deed]. Dan zal het gezag regeren. Het geld is om

het land te regeren. Drank als boete

geeft geen voordeel. Het voedt geen kinderen op.

Het prikkelt alleen de lippen. Iedereen die verdient

20 geld moet [dit] aan de bank geven, opdat de bank het voor hem be-

in nood is, de bank zal je het geld [terug] geven. Dan als het land 
156P5 a DA 4 to $\theta$ es w e $M$ wx $8>/$ e $D x x$

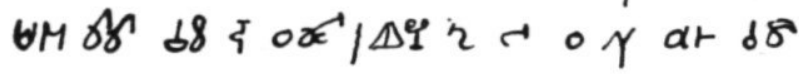
- bu as aepx।

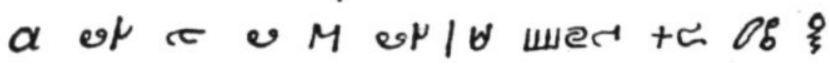

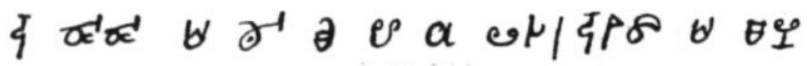

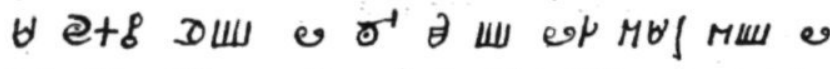

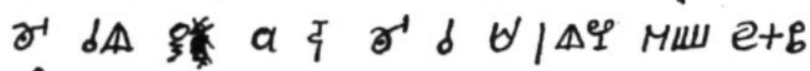
$\gamma \uparrow P D E M$ W B ob orm $w$ xb $w$ es orm Des ul a हीH

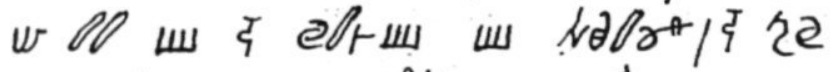
$\boldsymbol{\Psi} M$ र orimi

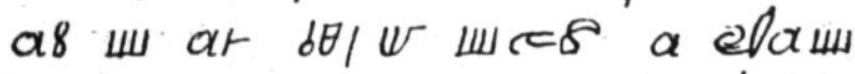

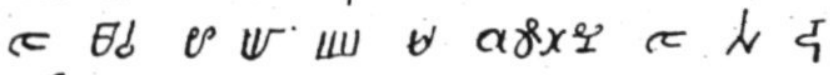
Del इ AN w w dR 6 M m दPन a De द trob/日 Mur a

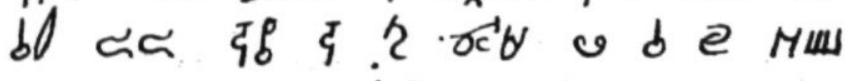

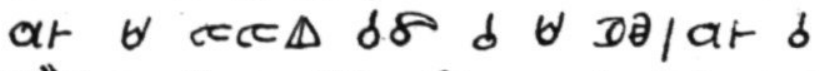
idן e द 0 Wf 
32

I piki piki a moni te a fiti, da lati moe moeiti bai masini foe wi e miri njanja, wi moe leri dei njanja poti na oso, bika wang ting o kong ala sanni o dede aga angiri.

5 a wipi di wi e wipi, de fositing ningge taki da na soso de be lo gi a wipi, na ini de maka de sineki mofo foe wipi ede, efoe wi ben sabi dan a na ben sa de, bika efoe sineki njang joe i moe fe-ele foe oli a boeba.

ro ke masa gadoe mi oesa mi gi gadoe tagi foe a sitarafoe di a gi mi na gorontapoe, tagi fi joe mi tata foe na sitarafoe foe gorontapoe, na wasi $\mathrm{mi}$ e wasi foe mi poeoe ala soendoe di mi be doe, ma mi na abi ogri ati, mi a boeng

I5 ati foe ala sama, mi foedini a sitarafoe di masa gi mi foe afirika di go na boesi, da ipi foe de sanni di e doe na ini a boesi na laoesanni, ma efoe a santa jeje naki na wang soema wi sa si efoe

20 ala de didibi sanni sa de moro, ala sa kaba, wi na moe deki taki wi sa libi eke

I het geld overal gepast verzamelt, dan moet het land moeite doen om machines te kopen opdat wij voedsel malen [verwerken]. We moeten

voedsel te drogen om in huis te bewaren, want een tijd zal komen

leren dat alles zal sterven van de honger.

5 Het zwepen dat wij doen: de negers van vroeger zeggen: Dan

zijn ze voor niets weggelopen voor de zweep in de dorens

[in] de bekken van slangen. We zijn weggelopen om het geselen. Als we het geweten hadden dan zou het niet [gebeurd] zijn. Als een slang je bijt, moet je bang zijn de huid vast te pakken.

Io Ach, Here God, ik Oesa, geef dank aan God voor de straf die Hij mij op aarde heeft opgelegd. Dank

$\mathrm{U}$, Vader, voor de aardse straf. Ik was

mij om weg te doen alle zonden die

ik heb gedaan. Maar ik draag niemand een kwaad hart toe, ik heb een

I5 goed hart voor iedereen. Ik verdien de straf die de Heer mij geeft voor [de] Afrikanen die gingen naar het bos. Dan, veel dingen die zij doen in het bos zijn dwaasheid. Maar als de Heilige Geest één mens treft, zullen wij zien

20 of al die duivelse dingen zullen stand houden. Alles zal ophouden. Wij moeten niet denken, dat wij zullen leven als 


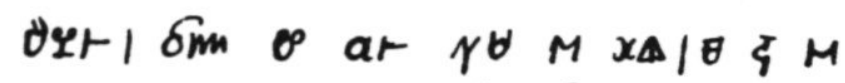
e ar $D$ dal a 2 бom/e $\theta$

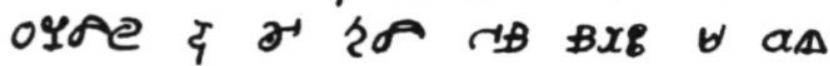

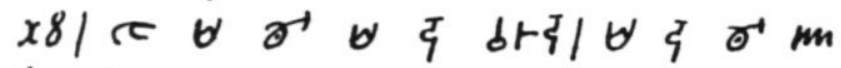

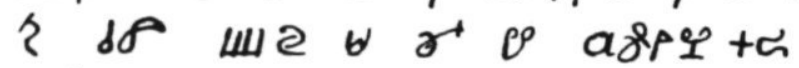
elam/ $\theta$ द om emir or m at

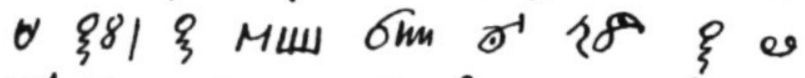

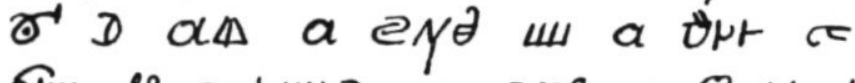
orm $P$ ellule a Bxg $Y \xi \forall \sigma^{\prime}$ d a $\mathrm{Ob}$ om. of द es at $\mathrm{Co}^{\mathrm{A}}$ e द $D$ DB पYa दDe। $\theta$ e $D$ xers ora If́MB

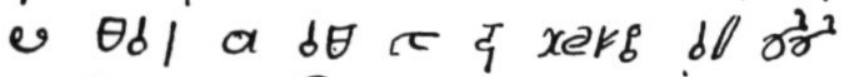

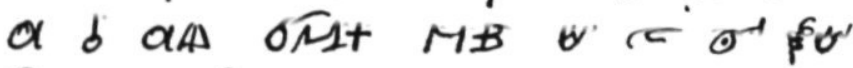
OMt I J'Pae Bxas/ME $2 d \theta$ were

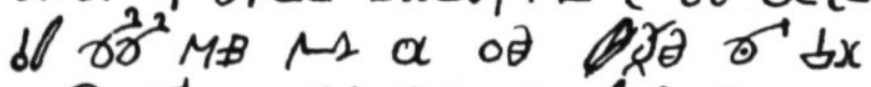
aर

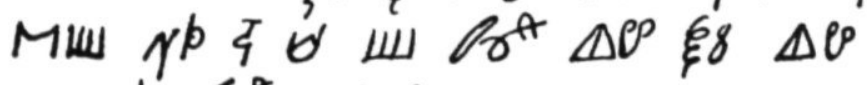
olx bे for $\triangle e^{\circ} \quad B 81$ 
I bakara, gadoe gi ala konde ing libi, ma na ing wi ala moe sabi, a wang gadoe, di de okanisi na be wanni teke keriki de abi leti, di de be de na sarana, de na be doe

5 wang sanni fosi de be gi afiika ningge sitaafoe, ma na gadoe si-efi be doe ala de dati, da efoe gadoe be wanni da wi be moe abi a sikolo foe a papira di gadoe gi wi, fosi a keriki kong dade be

Io da si taki gadoe de na wi ala tapoe.

wi na moe moeke bakaa makiti wi, na ini na boesi, ma wi moe resipeki bakaa, so eke wi masa, a sama di na resipeki santa jeje a sa abi gafaning eke de di be fede

I5 gafaning na jeisisi keresiti, efoe wang sama wisiwasi santa jeje eke foe a olo bokoero be pori aga a sondoe dati fesi sa tapoe na faja, efoe konni na de foe tapoe bigi feti bigi areng sa tapoe bigi feti.

I de blanken. God geeft elk land eigen leven. Maar Hem moeten wij allen kennen, de enige God. Toen de Aukaners geen kerk wilden aannemen hadden zij gelijk. Toen ze in Suriname waren heeft men niets

5 gedaan voor dat men de Afrikaanse negers dwangarbeid gegeven heeft. Maar God zelf had dit alles gedaan.

En als God gewild had, dan hadden wij de school moeten hebben voor het schrift dat God gaf, voordat de kerk kwam, dan zou men Io gezien hebben, dat God allen beschermt.

Wij moeten de blanken ons niet laten overheersen in het bos. Maar wij moeten de blanken respekteren als onze heren. Iemand die de Heilige Geest niet eerbiedigt verhovaardigt zich, gelijk zij die zich met vrees

I5 verhovaardigen tegenover Jezus Christus. Als iemand niet telt de Heilige Geest, zo als de oude bekoring bedorven was met de zonde, zijn aangezicht zal het vuur bedekken. Als er geen kunde is een grote strijd te voorkomen, grote regen zal de grote strijd beëindigen. 


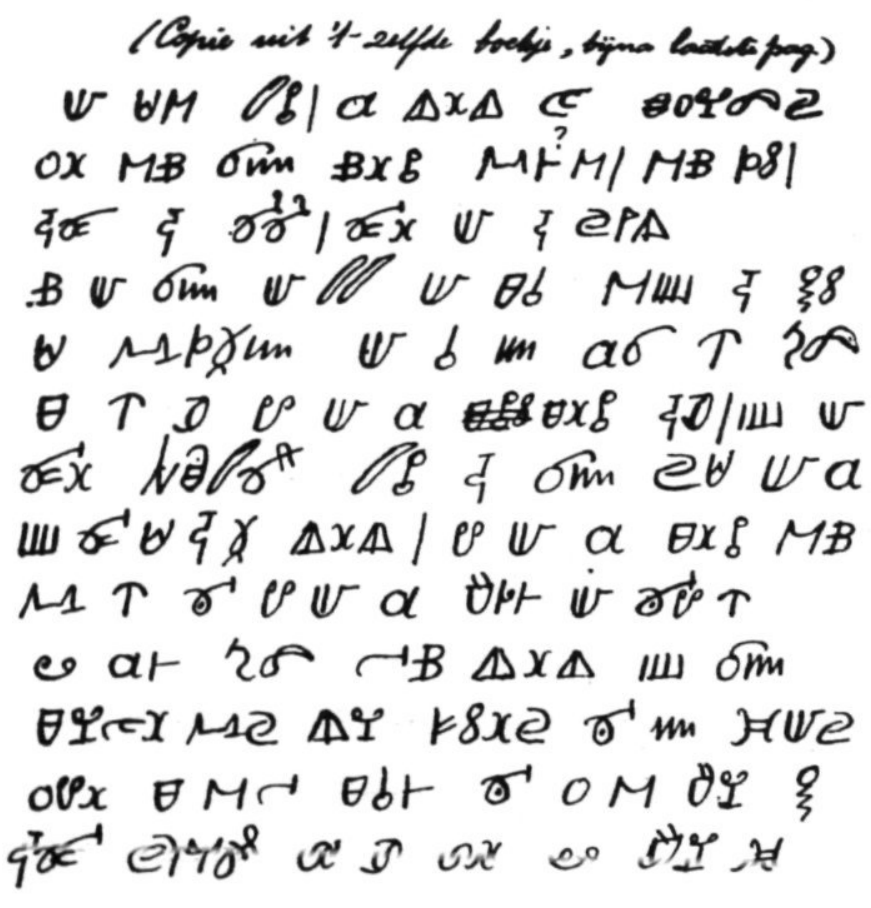

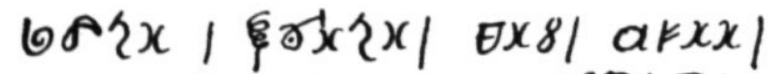

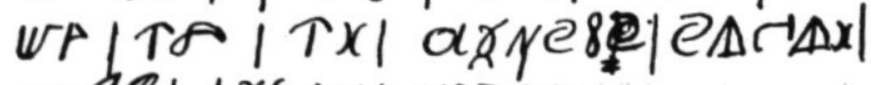
or 
(Copie uit 't-zelfde boekje, bijna laatste pag.)

I me de e taki, a bilibi di okanisi oli eke gadoe keriki fara eng, eke noto, naso na jeje, sori me na sibi ke mi gadoe mi tata mi masa efoe na dati

5 de fano-oedoe mi sa doe ala joe wanni ma joe moe gi mi a mariki ${ }^{1}$ namo, foe $\mathrm{mi}$ sori gorontapoe taki na gadoe side me a foe so de na oe bilibi, gi mi a mariki eke fa joe be gi mi a papira mi begi joe

ro wi ala wanni teke bilibi foe gadoe makandiri fasi bika petirisi be doe toemisi ogiri ma e ting masara be o eng baka da na so si-efi a moe oli wi baka toe.

janiwari, feberiwari, mariti, aprili, mei, joeni, joeli, doekositisi, sibetiberi, ooetiboe, nooefebiri, deisiberi.

I Ik zeg, het geloof dat de Aukaners houden als [met] Gods Kerk ver weg verwijderd, is als niets. Zo heeft de Geest het mij in mijn slaap getoond.

Ach, mijn God, mijn Vader, mijn Heer, als dàt

5 nodig is, zal ik doen met Uw wil [wat U wilt].

Maar Gij moet mij het teken geven in ieder geval, opdat ik de wereld tone, dat God mij gezonden heeft.

Als dit Uw overtuiging is, geef mij het teken gelijk

Gij mij het schrift gegeven hebt, verzoek ik U.

ro Wij allen willen Gods geloof aannemen,

gezamelijk. Want Petrus heeft erg

kwaad gedaan. Maar toen heeft de Heer hem weer aangenomen. Dan ook zo moet Hij ons weer aannemen.

januari, februari, maart, april, mei, juni, juli, augustus, september, oktober, november, december.

1 In het manuscript is 'makiti' (macht) doorgehaald, en werd 'mariki' (teken) geschreven. 


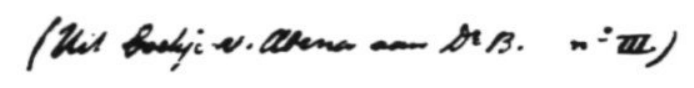

Q द व

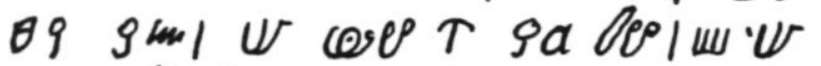

$x \Delta 1$ bar « e t

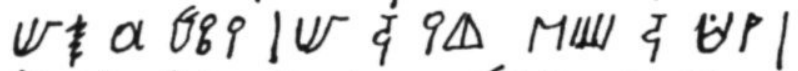

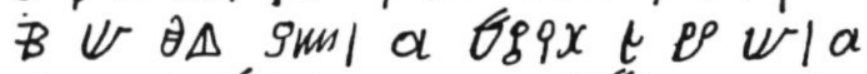
दD शण|k w a erfla or

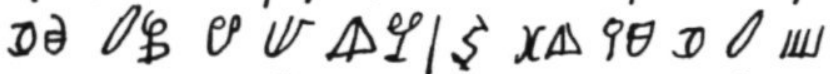

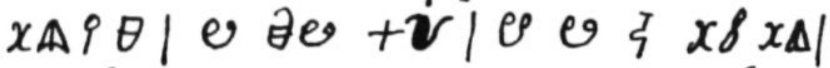

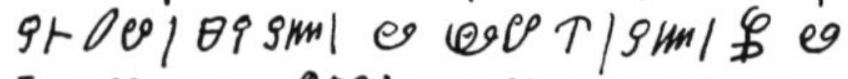

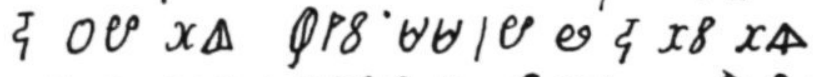

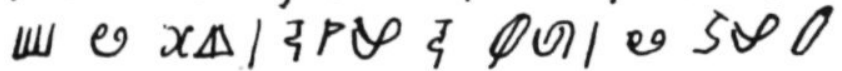

इP⿻ $Q$ Q

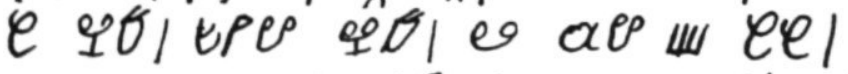

$\theta \theta \tau$ es MB SOAPlun a ep/ut

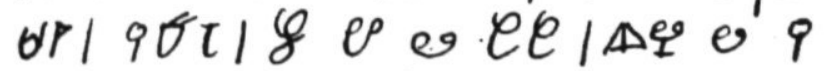

$\forall 6 \mid$ as a

$$
\text { ( } 6.2 .2 .20 .)
$$

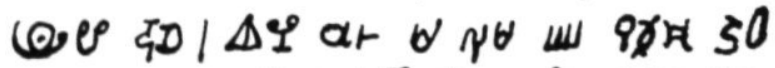

$M \times A$ as $\theta \mu+1 \theta$ द $0 \partial \Theta+v \leqslant 0$

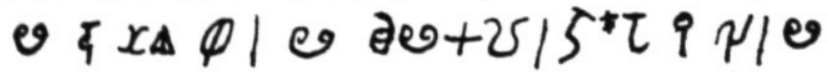


I da [disi] na a begi foe libi, bika libi soeti toe. masa gadoe, mi begi ga-a tagi, foe mi libi, pa-ato foe wi lowe ningge, a pakisari di joe gi mi, mi na sabi efoe na neti joe gi

$5 \mathrm{mi}$ a pakisa, mi na sabi efoe na dei,

ke mi lobi gadoe, a pakisari di gi mi, a na mo kaba, pe foe a kaba, a moe kong moro tapoe gi mi bika, wang libi sama moe ta foe libi sama, wi lowe ningge, gi wi na leti libi,

ro gara tagi, masa gadoe, wi begi joe, gadoe, poe wi na ogi libi boiti dede, gi wi na leti libi foe wi libi, na ini na boesi, wi wanni ta na ini na boesi, toe-oe toe-oe, mi begi joe, wi nja kaba, di-igi kaba, wi agi foe nja nja,

I5 mamating wi e ke wata ai, foe a gi, mi di dei, sapating, fi gi wi nja nja, bika wi sa dede, aga agi, masa gadoe, ke mi begi joe.

(ibid. IV.)

begi namo, bika ala de konde foe saoetoe wata e libi aga papira, ma wi lowe ningge namo

20 wi na libi boeng, wi lowe ningge, wan ting sa kong, wi

I Vervolgens het gebed om te leven, want het leven is ook zoet. Here God, ik verzoek, als het U belieft, opdat ik leve. Vergiffenis voor ons, weggelopen negers. De gedachte die Gij mij gegeven hebt - ik weet niet of 's nachts Gij mij

5 die gedachte gaf, ik weet niet of overdag. Ach, mijn lieve God, de gedachte die mij gegeven is, moet niet ophouden. In plaats van dat zij ophoudt moet zij sterker worden voor mij, want een mens moet menselijk blijven. Ons, weggelopen negers, geef ons het ware leven.

ro Als het U belieft, Here God, wij verzoeken U, God, trek ons uit het kwade leven. Verban de dood, geef ons het ware leven, opdat wij leven in het bos. Wij willen blijven in het bos. Werkelijk. Ik smeek U. Ons voedsel is op. Ons drinken is op. Wij hongeren naar spijs.

I5 's Morgens schreien we tranen opdat Gij geve 's middags, 's avonds dat Gij ons eten geeft, want wij zullen sterven van de honger, Here God, ach, ik smeek U.

Blijf bidden. Want alle landen van het zoute water leven met een schrift. Slechts wij, weggelopen negers, 20 wij leven niet goed. Wij weggelopen negers, er zal een tijd komen 
248

J. W. GONGGRYP \& C. DUBELAAR

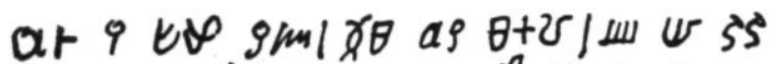

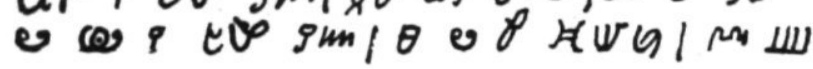

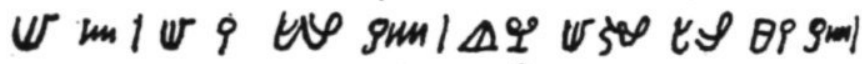

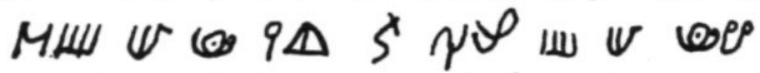

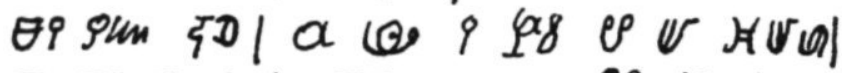

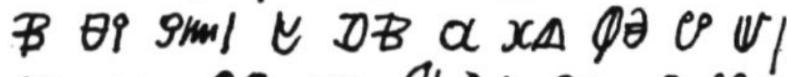

$v$ as $\varphi \phi$ ul OtSI sm $\rho \rho \rho$

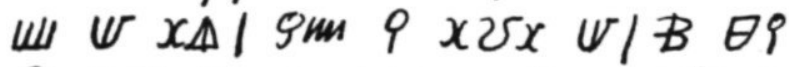

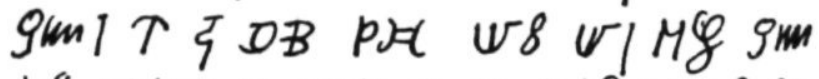

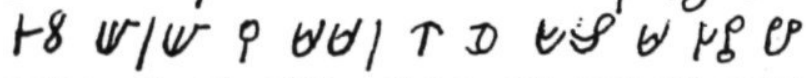

U/ as $b^{\prime}$ र

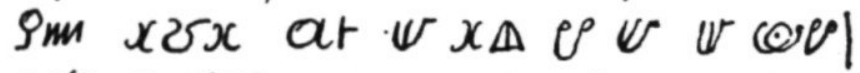

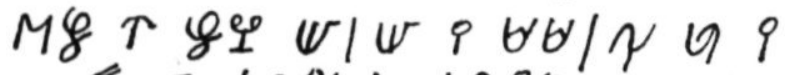

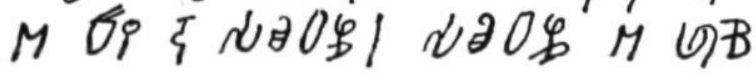

as opx /as Hil as kl as appxl

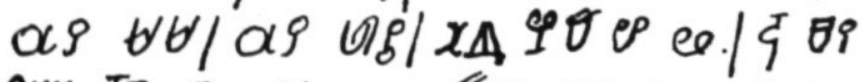

gim दD. i $x v x$ eo GY MB Rs a 6

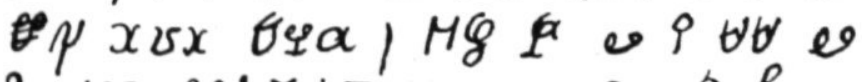

jeotes nutr 10 Mाu $\theta 9$ gum is a

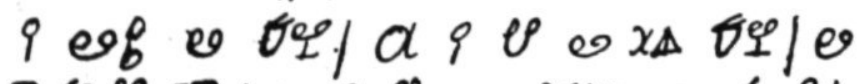

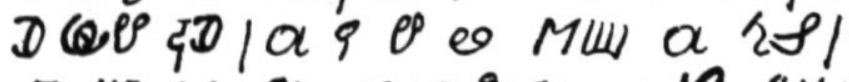

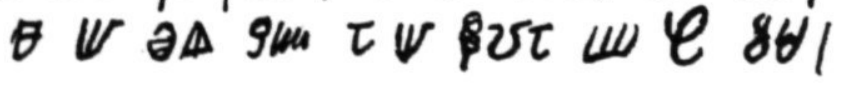

Downloaded from Brill.com@4/26/2023 03:19:56PM

via free access 
38

I ala sa dini gadoe, oema ana man ningge, foe mi wawang wi be sa dini gadoe, ma wi to toemisi, fa foe mi doe, mi sa dini gadoe, bika mi wanni dini masa gadoe. efoe mi be sabi wang konni foe mi begi

5 masa gadoe namo, a be sa soeti gi mi toemisi, ke masa gadoe, di moke a libi boro gi mi, mi abi boeng boeng foe tarawang, gadoe sa gi mi foe mi libi, gadoe sa rigeri $\mathrm{mi}$, ke masa gadoe, joe na moke notoe miti mi, efi gadoe

ro lati mi, mi sa dede, joe moe dini de piki ge $\mathrm{mi}$, aga de oema foe mi gi mi, mi begi gadoe rigeri ala mi libi gimi mi begi efoe joe fika mi, mi sa dede, kong si sa e pasa na gorontapoe, gorontapoe e seke

I5 aga ogiri, aga pina, aga pe, aga agiri, aga dede, aga siki, libi kaba gi wi, na masa gadoe namo sa rigeri wi baka eke fa a be kong rigeri bakaa, efi so wi sa dede wi lowe ningge falaoe, ma efoe masa gadoe wanni a

20 sa wiki wi baka, a sa gi wi libi baka, wi moe begi namoe, a sa gi wi efoe a wanni, ma wi lobi gadoe te mi figete foe nja tide,

I dat wij allen God zullen dienen, vrouwen en mannen. Wat mij betreft zouden wij God dienen. Maar wij zijn te dom. Wat moet ik doen? Ik zal God dienen, want ik wil de Heer dienen. Als ik de kunst verstond dat ik kon bidden

5 de Here God voortdurend, zou mij dit zeer lief zijn. Ach, Here God, die voor mij 's levens adem maakt, ik heb een goed hart voor anderen. God zal mij geven opdat ik leve. God zal mij besturen. Ach, Here

God, Gij moet mij niet in nood laten komen. Als God

ro mij verlaat, zal ik sterven. Gij moet mijn kinderen beschermen voor mij en mijn vrouwen voor mij; ik verzoek God bestuur mijn gehele leven voor me, verzoek ik. Als Gij mij verlaat zal ik sterven. Kom zien wat op aarde gebeurt. De wereld schudt

I5 van [het] kwaad, van gebrek, van pijn, van honger, van dood, van ziekte. Het leven houdt op voor ons, de Here God slechts zal ons wederom besturen, zo als $\mathrm{Hij}$ de blanken is komen besturen. Indien niet dan zullen we dood gaan. Wij weggelopen negers vallen flauw, maar als God de Heer wil Hij

$20 \mathrm{zal}$ ons weer wekken. Hij zal ons weer leven geven, wij moeten steeds bidden. Hij zal ons geven als Hij wil. Maar mijn lieve God, als ik heden vergeet te eten, 


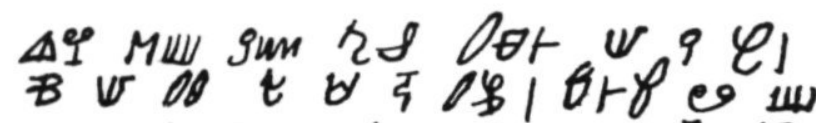

a of $T \omega$ s

द D

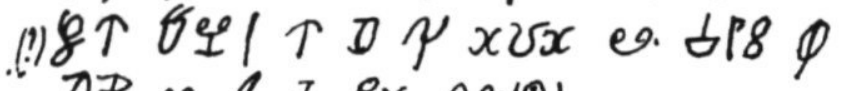

$D B$ or l द \& $x^{2}$ लामा

$$
\text { (ibiv. I): }
$$

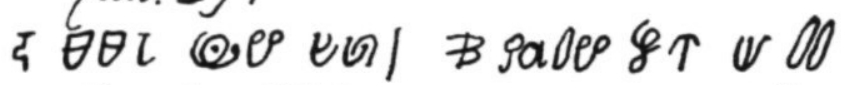

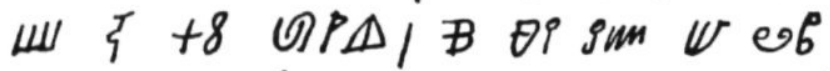

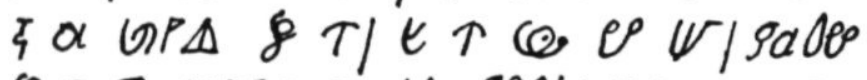

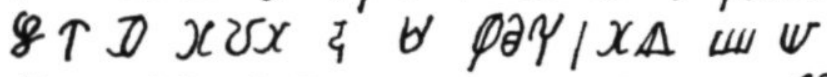

ค

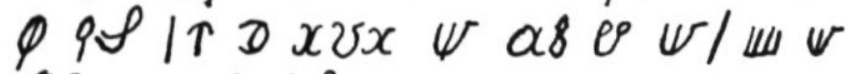

sponx P \&

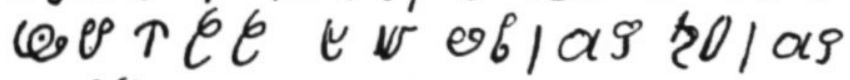

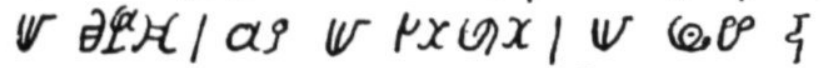

$x 8$ gun $t$ eser $\{x \Delta \phi \theta$ P el

(Bid. II):

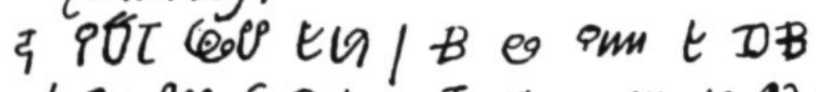

ol gaDes g

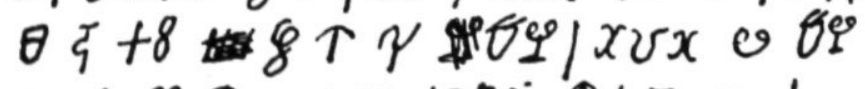

eces $r$ we GPA $\phi / \theta$ a $\phi x$ 
39

I bika efoe gadoe wanni tamara mi sa nja, ke mi tata di de na tapoe, parato wi foe a wipi joe be poeoe na wi ana towe na boesi wi teke baka, e wipi sama

5 fi joe baka, joe moe kong rigeri wi poiti boeng moke wi tang na kiri fasi.

\section{(ibid. I):}

na mamating begi disi, ke gaatagi fi joe mi tata foe na neti siibi, ke masa gadoe mi wiki na a sibi fi joe, di joe be gi mi, gaatagi

Io fi joe moe rigeri na de boroko, libi foe mi gi mi toe, joe moe rigeri mi mofo, foe a taki boeng sani, joe moe rigeri $\mathrm{mi}$ ati gi $\mathrm{mi}$, foe $\mathrm{mi}$ pakisiri boeng sanni toe, mi begi gadoe, ke mi begi joe nja nja di mi wiki, aga wata, aga

$15 \mathrm{mi}$ losoetoe, aga mi pirisiri, mi begi na

leti gadoe di gi wi na libi boro gi wi.

\section{(ibid. II):}

na sapating begi disi, ke wi gadoe di moke wi, gaatagi fi joe, foe na rigeri foe de boroko, ma na neti fi joe kong baka, rigeri wi baka 20 wi begi joe foe wi siibi boeng, ma a tjari

I want als God wil zal ik morgen eten.

Ach, mijn Vader die hier boven zijt, vergeef ons dat wij de zweep, die Gij uit onze handen hebt genomen en weggeworpen in het bos, hebben teruggenomen om mensen te zwepen

5 voor $\mathrm{U}$ wederom. Gij moet komen besturen, ons armzaligen, goed, opdat wij blijven in de zuiverheid.

Dit is het morgengebed. Ach, dank U, mijn Vader, voor de slaap van deze nacht. Ach, Here God, ik ontwaak uit de slaap, die Gij mij gegeven hebt. Dank.

Io Gij moet besturen het ontwaken. Geef mij ook leven. Gij moet besturen mijn mond opdat hij spreke goede dingen. Gij moet besturen het hart voor mij, opdat ik ook goede dingen denke. Ik verzoek God, ach, ik verzoek $\mathrm{U}$ voedsel, nu ik wakker ben, en water, en

I5 mijn lust, en mijn genoegen. Ik bid de ware God, die ons gaf de levensadem, aan ons.

Dit is het avondgebed. Ach, onze God, die ons maakte, dank $U$ voor Uw bestuur van de morgen.

Maar Uw nacht komt weer, bestuur ons weer. 20 Wij vragen $U$ dat wij goed slapen. Maar jammer 


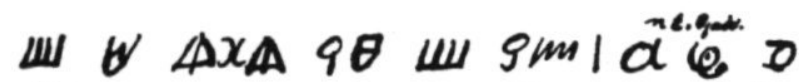
$\xi+P$ a $x \Delta$ eo $e / D B \forall$ Dar. 0

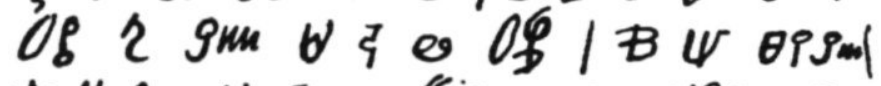

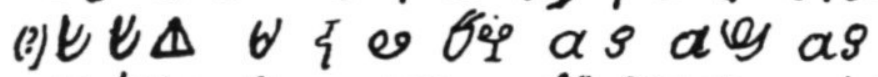

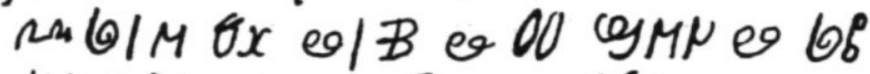

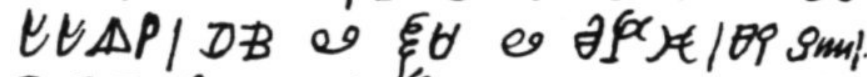
(?) $\begin{aligned} & T \\ & 0\end{aligned}$

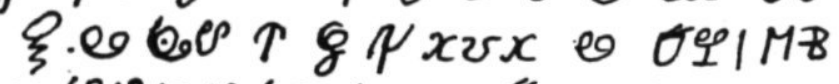

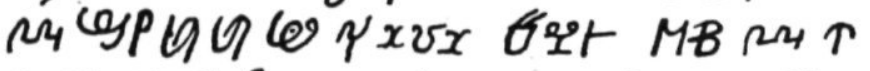

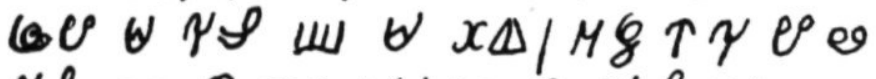

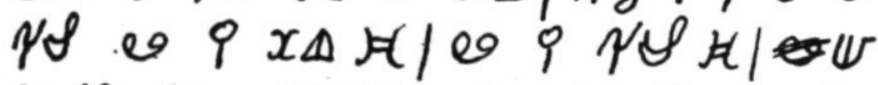
cols gum as at $w$ as fixtr עل 9000 smi les as D $\triangle x A /$ es OO E

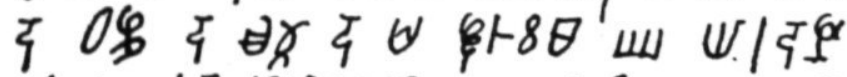

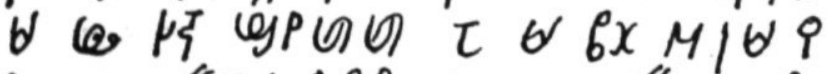

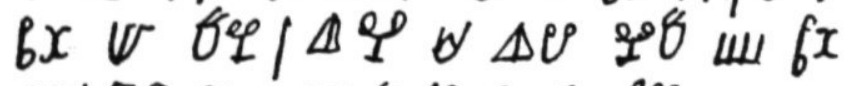

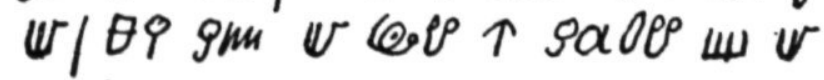
$x \mathbb{1}$ 
40

I foe de bilibi sama foe gadoe, a be moe darai a libi gi wi, moke de taawang si taki wang gadoe de na wi tapoe, ke mi masa gadoe, didibi de na wi kaba a ga aje aga

5 faja, e bari wi, ke wi tata jeepi wi jaki didibii, moke wi fede wi losoetoe, masa gadoe, joe na moe kiri wi pe fi ke gi wi aga dede da wi begi joe fi kong rigeri wi baka, eke fa jeisisi be kong rigeri bakara eke fa joe

Io be gi de konni foe de libi, efi joe kong gi wi konni wi sa libi toe, wi sa konni toe, mi begi gadoe aga ala $\mathrm{mi}$ ati toeoetoeoe foe masa kong rigeri wi, eke fa a wanni, gatagi gadoe, wi ati moe bilibi, wi tata di de

I5 na tapoe na loekoe na de feletima foe mi, na so de be pina jeisisi te de kiri eng, de sa kiri mi baka, bika de bigi kaba foe kiri $\mathrm{mi}$, masa gadoe mi begi joe gaatagi foe $\mathrm{mi}$ libi.

I voor de gelovigen in God moest het leven voor ons veranderen, opdat de anderen zouden zien dat er één God boven ons is. Ach, mijn Heer, God, de duivel vervolgt ons met ijzer en met

5 vuur. Hij lokt ons, ach, onze Vader, help ons wegjagen de duivel. Maak dat wij vrezen onze lust. Heer God, Gij moet ons niet kwaad doen. In plaats van ons te doden verzoeken wij $\mathrm{U}$ ons weer te komen besturen, zo als Jezus de blanken is komen besturen, zoals

Io Gij hun kunst gegeven hebt om te leven, als Gij ons komt geven kunst zullen wij ook leven. Wij zullen ook verstandig worden. Ik bid God met geheel mijn hart oprecht dat de Heer ons komt leiden zo als Hij wil.

Als het $\mathrm{U}$ belieft, God, ons hart moet geloven. Onze Vader, die is

I5 hierboven, zie niet naar die vijanden van mij. Zo

hebben zij Jezus doen lijden, totdat zij Hem doodden. Ze zullen mij ook doden. Want ze begonnen mij reeds te doden Heer God, ik smeek $U$ als het $U$ belieft laat mij leven. 


\section{SUMMARY}

THE PAPERS OF AFAKA IN HIS DJUKA SCRIPT

A survey of the evolution of this script appeared in an article in the N.W.I.G. 40, 1960, p. 63-72, while in Opbouw, December 1960, some further particulars were given.

Thanks to the coöperation of the Catholic Bishop of Surinam, Monsignor S. KUyPERs, we found among the papers of the late Father F. Morssink, C.s.s.R., a booklet in Djuka script, containing the principal prayers and religious formulae of the Catholic Church, and the Catechism, transcribed by Father Morssink in Djuka script in conformity with the publication Passi foe Hemel in the native language, and in Latin script for use in the coastal regions of Surinam.

What was of even more importance, we found copies of papers in Djuka script which had been given or transmitted to Father MorSSINK by AFAKA, who died on 8th July, r9r8.

With some exceptions - notably some papers given to Dr. C. BonNe in about 1917 - all that was known to exist in Djuka script consisted of some short sentences, of little importance other than as samples of AfaKa's script.

The papers in his hand given to Father Morssink indicate not only the sympathy of this originally unlettered Djuka with the Catholic Church, but also his obedient subjection to "the Lord God, the Almighty Father" who rules everything, and likewise "modern" points of view, such as acceptance of technical progress, including the banking of money, and rejection of corporal punishment. In reading AFAKA, who suffered for many years from a painful disease, one is reminded of the Biblical story of Job.

AFAKA's script may not be of any practical importance at present. His mental achievement, however, cannot be denied. 